\title{
The Reconstruction of a Race of Primitive Angiosperms.
}

\author{
BY
}

\section{ETHEL SARGANT, F.L.S. \\ With twenty-one Figures in the Text.}

$7 \mathrm{HE}$ origin of Angiosperms is perhaps the most important problem 1 which botanical morphology has yet to solve. The advance of knowledge, which has thrown light on so many questions formerly to all appearance insoluble, seemed for a long time rather to obscure than to illuminate this subject. But of late some progress has been made. New facts have been contributed to the scanty evidence hitherto available, and several botanists have attempted to collect and piece together all such evidence, scattered, fragmentary, and insufficient as it is.

On the one hand, our knowledge of the origin and development of the embryo-sac, both in Angiosperms and Gymnosperms, is more extensive and more precise. The structure of Angiospermous seedlings has been examined from a phylogenetic standpoint. ${ }^{1}$ Dr. Wieland has described the bisexual strobili of the American Bennettiteae, which offer so many points of resemblance to the flowers of Angiosperms (89).

On the other hand, we have treatises and speculations on the general question. The Morphology of Angiosperms (Coulter and Chamberlain, 19) is written throughout from a phylogenetic standpoint. The vexed question of the comparative antiquity of Monocotyledons and Dicotyledons has been revived on taxonomic (Hallier, 34) as well as on biological and anatomical grounds. ${ }^{2}$ The origin of the Angiospermous flower has been discussed. ${ }^{3}$ Finally, in a recent paper on the origin of Angiosperms (4), Messrs. Arber and Parkin have sketched out a possible line of descent for Angiosperms from Pteridosperms.

The evidence thus brought together falls naturally under two heads. On one side we have an enormous mass of morphological detail concerning living Angiosperms - at once the largest, the best known, and the most

1 Sargant (72); Tansley and Thomas (87); Anonymous (2); T. G. Hill (40, 41); A. W. Hill (39)。

${ }^{2}$ Henslow (38); Balfour (8); Lyon (57, 58); Sargant $(72,73)$.

${ }^{3}$ Benson (9); Robertson, C. (68); Oliver, F. W. (62); Scott, D. H. (80).

[Annals of Botany, Vo1. XXII. No. LXXXVI. April, 1908.] 
highly differentiated group in the vegetable kingdom. Their classification has occupied many generations of botanists, and the result is no doubt in the main a truly natural system ; that is to say, a system based on real affinities. With such wealth of evidence to draw upon, we might expect to work backwards with certainty from the most primitive forms which we know to their common ancestors - a race which of course has been long extinct. But this is so far from being the case that authorities are still hopelessly divided on the interpretation of the facts.

On the other side is all we know about the forms, living or extinct, which may have stood near the main line of Angiospermous descent. The difficulty in this case is want of evidence. The floral structure of Angiosperms by itself isolates them from all other groups, without taking other characters into consideration.

In the most recent attempt to reconstruct the pedigree of Angiosperms (Arber and Parkin, 4, p. 77) ${ }^{1}$, the authors start from a Palaeozoic ancestor, which they place among the newly recognized group of Pteridosperms. They trace the development of the flower through a series of hypothetical forms-pro-anthostrobilus (p. 63, Fig. 4) ; eu-anthostrobilus (p. 44, Fig. I)up to the more complex form of Ranal flower, Magnolia or Liriodendron. While the female sporophyll of the pro-anthostrobilus is suggested by that of Cycas, the whole scheme of the fructification is intermediate between the Angiospermous flower, on the one hand, and the bisexual strobili described in the American Bennettiteae by Dr. Wieland, on the other. The euanthostrobilus makes a much nearer approach in detail to the Ranal type, considered by the authors as the most primitive form of flower now in existence.

It will be seen that even this bare outline of a possible pedigree for Angiosperms depends largely on two recent additions to our knowledge : on the recognition of the Pteridosperms as a group of primitive seedplants, and on the description of bisexual strobili among the Bennettiteae.

The memoir (4) was not published in full until July, 1907, but it was communicated to the Linnaean Society at the meeting on March $2 \mathrm{I}$ of that year, when the authors read an abstract which gave rise to a discussion on the Origin of Angiosperms (3, p. I3).

On the earlier date I was still engaged in preparing a course of lectures on the Ancestry of Angiosperms, which were delivered for the London University in May and June, I907. The aim of the course was to reconstruct the common stock from which I assumed Monocotyledons and Dicotyledons to be descended. This stock was referred to as the Primitive Angiosperm. The subject proved sufficient to occupy eight lectures without entering at any length into the vexed question of the primitive flower.

1 The Table of Relationships here quoted is reproduced, by kind permission of the authors, on p. 137 of this memoir. 
The present paper is an abstract of those lectures. It may be considered as a complement to that part of Messrs. Arber and Parkin's memoir which deals with the immediate predecessors of our living Angiosperms. The evidence brought together in that memoir relates mainly, though not exclusively, to floral structure. I am in complete agreement with the general conclusions reached by its authors. Accordingly, I have attempted no separate reconstruction of the flower of the Primitive Angiosperms.

The evidence considered in the present paper, then, is in the main derived from the study of living Angiosperms. This evidence will be used to reconstruct a comparatively recent race of plants-the latest ancestors which Monocotyledons and Dicotyledons had in common. In dealing with their floral structure Messrs. Arber and Parkin's results will be accepted as a working hypothesis.

Before discussing the evidence on which we may hope to reconstruct the Primitive Angiosperms, it is essential to inquire whether such a race ever existed. Do all our living Angiosperms spring from a common stock ? If not-if they have been derived from different descendants of the original Pteridosperm, at several epochs and through distinct lines of descent-the problem becomes very much more complicated. Indeed, in the present state of our knowledge it could not be profitably attacked.

The argument in favour of the monophyletic origin of Angiosperms may be briefly summarized thus: The characters which Monocotyledons and Dicotyledons have in common are too numerous and too uniform to have been acquired independently in response to similar conditions. They must be derived by inheritance from a common stock-a race of Angiosperms, since it possessed the characters common to both classes within that group.

This argument appears to me conclusive, but, while the probability of such origin is called in question by botanists of authority, the truth of it cannot be assumed without discussion. The present essay is, therefore, divided and subdivided as follows :-

I. Reasons for believing that Angiosperms are monophyletic.

II. Reconstruction of the primitive race of Angiosperms.

I. Floral structure.

2. Stem anatomy.

3. Number of cotyledons.

4. Minor characters considered in connexion with phylogenetic schemes.

\section{Monophyletic Origin of Angiosperms.}

The remarkable isolation of Angiosperms in the vegetable kingdom is due of course to the absence of intermediate forms either living or fossil.

1 Balfour (8); Coulter (18); Coulter and Chamberlain (19), p. 283. 
That such forms were once present is inferred from the sudden appearance of certain characters in this group. Angiosperms possess structures which are unique : for instance, the flower, the carpel, the endosperm. These members are found in Monocotyledons and Dicotyledons alike, but are absent from all other groups. The history of their origin has not yet been recovered : it is not even clear what members represent them in the lower plants.

The flower, the carpel, and the endosperm then have been evolved by Angiosperms and their ancestors since the epoch when they were represented by a race of Pteridosperms. The question is, whether these members appeared in one line of descent or several. Monocotyledons and Dicotyledons must have had a common ancestor at some time, but was that ancestor in essentials an Angiosperm? Did it-to take the simplest test-possess a true carpel?

The problem so stated is reduced to its simplest terms. We suppose that Angiosperms were derived from two races only, one of them giving rise to Monocotyledons, the other to Dicotyledons. We agree to consider for the moment one character only among those peculiar to the two classes, neglecting not only the other two unique characters, but also the numerous minor features which they have in common.

If the common ancestor $X$ did not possess true carpels, then carpels must have been evolved independently by Monocotyledons and Dicotyledons. Naked seeds were transmitted by $X$ to its branches $Y$ and $Z$. In the course of generations the seeds of both races have become enclosed in a carpel. There is no evidence to show how this occurred. The sporophyll might gradually close round one or more ovules, or some sort of cupule (Oliver, 62) might become a carpel. But though the sporophyll or the cupule is inherited from $X$, each step in its transformation must have been taken independently by $Y$ and $Z$, in response no doubt to the demands of the environment.

In this way each race might well acquire a carpellary organ, but the chances are certainly much against the evolution of precisely similar members in both. The Angiospermous carpel combines several functions. It protects the ovule, and also collects pollen-grains and directs the course of their tubes. But in other groups these functions are not always performed by the same structure. In the Bennettiteae the ovules are sheltered by peltate scales, which serve as a very efficient protection to them and also to the seeds. The pollen, however, is still collected by the integument of the ovule, and germinates on the micropyle.

If in response to their surroundings both races developed organs which would at once protect the ovule and secure its pollination, we should still expect to find some constant difference in the carpels of the two races, due to their distinct race-history. But no such difference exists. There are indeed single carpels and carpels united into a pistil ; superior and inferior 
ovaries; stalked stigmas and sessile ones. But all these forms occur indifferently among Monocotyledons and Dicotyledons. The natural inference from the facts is that carpels were derived by inheritance from an ancestral race common to both classes.

The improbability of a multiple origin is of course very greatly increased if Angiosperms are derived from more than two non-Angiospermous races; that is, if we suppose carpels to have been evolved in three or more parallel lines of descent.

A similar argument applies to two other characters, which are most conveniently treated together, the germination of the embryo-sac, and the formation of the endosperm in Angiosperms. The strength of this argument appears very great when it is considered ( $I$ ) that the first nuclear divisions within the embryo-sac are highly characteristic of Angiosperms. In other words, they differ in a marked way from the first steps in the germination of any other megaspore. (2) That the origin of the endosperm from a fusion of three nuclei is still more characteristic, and that its morphological value is still unknown. (3) That both processes, though complicated and therefore offering many possibilities of variation, are remarkably uniform throughout the group. The very few exceptions recorded belong for the most part to parthenogenetic or apogamous species, or to forms clearly degraded by parasitism or similar causes. Such forms can hardly be regarded as primitive.

These considerations point to a very long period during which the Angiosperms as we know them now were evolved - a period long enough to stamp such well-defined characters on the race, and also to allow of the disappearance of the numerous intermediate forms which must have existed once.

The discovery of the origin of the endosperm from a fusion of three nuclei is quite recent, and as the literature of the subject is scattered we may briefly discuss the strength of the evidence. Up to 1898 the primary endosperm nucleus was believed to arise from the fusion of the two polar nuclei in the embryo-sac (Strasburger, 84). In that year Nawaschin (61) showed that a third nucleus takes part in this fusion. He was working on Lilium Martagon and Fritillaria tenella, and in these plants he identified the third nucleus as one of the two generative nuclei derived from the pollen-tube. The other, of course, had fertilized the ovum. It was known that two generative cells entered the embryo-sac, but it had been previously believed that when the nucleus of one had fused with the nucleus of the ovum the second generative cell broke down like the synergids.

Nawaschin's discovery was soon confirmed by the publication of Guignard's independent researches (32). Since 1899 a literature has grown up on this subject. The most recent résumés are those of Guérin (30) 
and Ernst (24). The section devoted to the subject in Coulter and Chamberlain's Morphology of Angiosperms (19) gives a list of references up to 1903 . In this work, however, the authors express themselves with a caution which even in 1903 appeared exaggerated to many morphologists. They remark on the wide distribution of the phenomenon, but add: - Probably it is not safe to infer the general occurrence of double fertilization, although the observations already include sixteen families, about forty genera, and over sixty species.' Sixty species is, of course, a very small fraction of the whole number of Angiosperms, but when they represent forty genera and sixteen families of very diverse affinities the evidence covers a good deal of ground. The strongest point in the case, however, is the absence of evidence to the contrary. Excepting apogamous species and anomalous cases of that kind, the endosperm has been found to arise from such a fusion as Nawaschin described wherever its origin has been carefully traced. The partial exception of Peperomia will be discussed later.

Evidence is still accumulating in the same sense. My list to the end of 1907 only reaches seventy-eight species, representing fifty-two genera and twenty-two families, but it is no doubt very incomplete. Considering the difficulties of observation, even this is a considerable body of evidence to be collected in nine years. It justifies botanists in assuming that the process of double fertilization is universal among Angiosperms.

Before considering the views now held on the homology of the endosperm, it will be convenient to review the facts very briefly.

The female prothallus of Pteridophytes is formed by the germination of the megaspore, and is fully developed at the period when the oösphere is formed within the archegonium.

The female prothallus-the so-called endosperm-of Gymnosperms arises by division of the nucleus within the megaspore or embryo-sac. Nuclear division is followed after some nuclear generations by cell-division. In the majority of cases the embryo-sac is filled with prothallial tissue before archegonia appear, and therefore this tissue does not develop further after fertilization.

The female gametophyte is quite clearly defined in both groups: $\cdot$ its development begins with the germination of the megaspore and ends with the act of fertilization. Moreover, gametophytic tissue cannot be mistaken, because the nuclei within it have only half the number of chromosomes characteristic of sporophytic tissue.

The female gametophyte of Angiosperms undoubtedly begins with the division of the embryo-sac nucleus, for the embryo-sac is acknowledged to represent the megaspore. Three successive mitoses give rise to eight nuclei within the embryo-sac-one of them the nucleus of the ovum. So far we are no doubt dealing with the gametophyte, yet already -in certain genera at any rate-Overton's test fails us. In these genera the double or 
sporophytic number of chromosomes appear in an arbitrary way in the chalazal nucleus of the second generation. But we do not know whether this remarkable anomaly is general or even common.

After fertilization two distinct bodies, the embryo and the endosperm, are formed in the embryo-sac, and they shortly fill it to the exclusion of all other tissue. The embryo is derived from the fertilized ovum, and of course belongs to the succeeding generation-the young sporophyte. The endosperm is derived from the union of three nuclei: two belonging to the female gametophyte of the mother plant, and one to the male gametophyte of the plant whose male element has entered the fertilized ovum. The synergids and antipodals disappear sooner or later: there is then no trace left in the embryo-sac of the female gametophyte as it existed before fertilization, and no tissue whose nuclei show the gametophytic number of chromosomes.

The only possible representative of the female gametophyte is the endosperm, and before 1898 most botanists considered it to be a belated female prothallus. This view, though sometimes attributed to Hofmeister, was in fact first maintained by Strasburger (85, pp. 137-I39) in 1879.

Le Monnier (53) published an alternative hypothesis in 1887 . He regarded the union of the polar nuclei as a sort of fertilization. The upper polar nucleus is sister to that of the ovum: it may well be considered as a female nucleus. The lower polar nucleus must then represent the male element. The endosperm is developed as a result of their union: it is therefore a short-lived misshapen embryo.

Botanists are still divided between these two camps, though Nawaschin's discovery of $\mathrm{I} 898$ has certainly increased the number of Le Monnier's followers. But it is no part of my plan to discuss their rival claims here. The pregnant fact in dealing with the ancestry of Angiosperms is that the question is still undecided. Either view can be held, and is held, by botanists of undoubted authority. In other words, we have so far no links, living or fossil, which enable us to trace the historical development of the endosperm in Angiosperms with any degree of certainty. ${ }^{1}$

Such evidence may be sought in two directions. We may examine the endosperm formation among aberrant Angiosperms, particularly among such forms as we are disposed on other grounds to consider primitive in structure. Or we may seek for some suggestion of the origin of the endosperm in the comparative structure of the Gymnospermous prothallus.

Knowledge of the minute structure of living plants is as yet so far from complete that we may still hope to find an Angiospermous embryo-sac in which the endosperm shows some decided trace of its origin-whether it prove to be a belated prothallus, a specialized sporophyte, or some other

1 Miss Berridge's interpretation of certain facts recently described in Ephedra may perhaps afford a clue. See p. I33. 
member. So far, however, this hope has grown fainter with every advance in knowledge.

Starting from the other side of the gulf, much has been done of late years to investigate the origin and development of the male and female gametophyte among Gymnosperms. The variety of structure in allied genera is astonishing, particularly when contrasted with the uniformity of Angiosperms. But while the identity of the food-tissue in the embryosac with the prothallus of Pteridophytes is clear in every form, no comparison with the endosperm of Angiosperms is even suggested by the development of such food-tissue, except perhaps among the Gnetaceae.

Accordingly, I propose to discuss first the anomalous embryo-sacs hitherto described among Angiosperms, and then to refer very shortly to the isolated cases of Gnetum and Ephedra.

The most complete account of the Angiospermous embryo-sac before fertilization is given in Coulter and Chamberlain's Morphology of Angiosperms (19), published in 1903. Guérin's more critical account (30) of 1904 is substantially the same. Both authorities remark on the extraordinary uniformity of this structure. The number of exceptions which they record is certainly very small compared with the number of species investigated. Even this small number should, I think, be considerably reduced, but on the other hand two species of Cypripedium must be added (Pace, 63).

Species belonging to five genera are described as showing considerable deviation from the normal type. They are:-

Peperomia pellucida and P. hispidula.

Gunnera-several species, but chiefly G. Hamiltoni.

Tulipa sylvestris and T. Celsiana.

Fuglans nigra and F. regia.

Trillium grandiflorum.

The anomalies in Peperomia pellucida were first described by Campbell (15) in 1899. A fuller and rather different account was published in the following year by Johnson (47), including observations on allied forms. Johnson has quite recently described a second species of Peperomia (49). Its endosperm formation shows anomalies similar to those of $P$. pellucida, but with certain interesting departures from that type.

In Peperomia, as in Lilium and other genera, the embryo-sac mother-cell becomes the embryo-sac without division. In $P$. pellucida sixteen nuclei are formed within the embryo-sac by repeated division of the original nucleus and its descendants. These nuclei are distributed pretty evenly in the peripheral layer of cytoplasm. One near the micropyle becomes invested with a definite mass of cytoplasm and can afterwards be recognized as the nucleus of the ovum. A neighbouring nucleus, which generally lies immediately under the micropyle, is likewise invested by cytoplasm, and 
the naked cell thus formed may represent a synergid. Eight nuclei mass together and after fertilization fuse to form the primary endosperm nucleus. The six nuclei which remain retain their parietal position and are cut off by walls from the cytoplasm of the embryo-sac. In the end they are crushed and absorbed by the developing endosperm.

No male nucleus has been identified in the group which becomes the primary nucleus of the endosperm. But this may be due to the absence of the stages which immediately succeed the act of fertilization in the preparations examined. For in all the cases described the male nucleus was about the same size as the nucleus of the ovum with which it was fusing. This indicates that it had entered the ovum some time. A similar nucleus within a group of eight would, of course, be indistinguishable from them.

The history of $P$. hispidula is similar, but not identical (Johnson, 49). In the eight-nucleate embryo-sac, two nuclei are near the micropyle and six at the chalazal end. The succeeding mitosis forms twelve chalazal and four micropylar nuclei. One of the latter becomes a well-defined ovum : the other a synergid. Two micropylar nuclei travel into the centre of the embryo-sac, where they fuse with the twelve chalazal nuclei. This fusion of fourteen nuclei becomes the primary nucleus of the endosperm.

The allied genera, Piper, Heckeria, and Saururus, were found by Professor Johnson (48) to form perfectly normal embryo-sacs, and he concludes that the peculiarities of Peperomia must be considered as derived from the usual type rather than primitive. The facts just described support this conclusion. In primitive species we should expect the endosperm to be better developed than in the normal embryo-sac-nearer, that is, to the original structure, whether gametophyte or sporophyte, from which the tissue familiar to us has been reduced. But in both species of Peperomia the endosperm in the mature seed consists of forty or fifty cells only, and is of very small bulk compared to the perisperm, which is the effective foodtissue, Indeed all analogy goes to show that a fusion of many nucleieight in $P$. pellucida and fourteen in $P$. hispidula - is far more likely to produce a small mass of short-lived tissue than a vigorous body capable of development into a permanent organ.

Peperomia stands alone as a normal deviation from type. For though Schnegg (79) has found similar features in the embryo-sac of Gunnera, he gives very strong reasons for thinking that in the species examined the embryo is formed without fertilization. If so, the example is irrelevant. For when the generative nuclei never enter the embryo-sac the origin of the endosperm must be as irregular as that of the embryo, and its formation is likely to be abnormal in other respects.

Of the three genera which remain in the list of exceptions on p. 128, the only one which need concern us is Tulipa. In the two species, T. sylvestris and T. Clusiana, Guignard (33) found that the embryo-sac before fer- 
tilization contains eight nuclei, without any trace of cell-formation and without the usual very characteristic orientation. The two which later act as synergids are sometimes distinguished by their smaller size, and the lower polar nucleus is from the first conspicuously different from the rest. The remaining five are precisely similar to each other: no one of them can be picked out as the future egg-nucleus. Tulipa Gesneviana, however, has a perfectly normal embryo-sac.

This fact alone would indicate that the peculiarities of the species described can hardly be a survival of primitive characters. Indeed, the deviation from the usual structure is not very great, and may be more apparent than real. The irregular orientation clearly depends largely on the absence of a central vacuole. It does not follow that no difference exists between the five nuclei, which later behave quite normally as egg-nucleus, upper polar nucleus, and antipodal nuclei, because we cannot perceive such difference. To trace the formation of these nuclei in greater detail than Guignard has done would be interesting. In Tulipa Gesneriana Ernst has shown that each nucleus in the chalazal tetrad is built up of more chromosomes than go to each of the micropylar tetrad. If this should prove to be the case in Tulipa sylvestris and $T$. Clusiana also, three of the five similar nuclei must be marked out as antipodals from their first formation. The egg-nucleus must be one of the two formed with the reduced number of chromosomes.

A similar but less marked absence of polarity is shown in certain exceptional embryo-sacs of Trillium grandiflorum according to Ernst (23), and of Fuglans nigra according to Karsten $(50 \mathrm{a})$. But in the large majority of individuals examined both observers found the embryo-sacs nearly if not quite normal. These genera should certainly not be included in such a list as this.

The species of Cypripedium described by Miss Pace (63) are C.spectabile and $C$.parviflorum, with corroborative sections from two other species. The embryo-sac mother-cell divides once: the upper segment soon perishes, the lower becomes the embryo-sac. After division of its primary nucleus, both daughter-nuclei divide again: the mature embryo-sac contains four nuclei. At the time of fertilization three nuclei are surrounded by delicate cell-walls, and orientated like an egg-apparatus: the fourth lies near the chalaza (63, Figs. 29, 30).

In entering the embryo-sac the pollen-tube seems to push the nucleus of one synergid-like cell in front of it. This nucleus passes to the chalazal end and fuses with the fourth nucleus and with one of the generative nuclei from the pollen-tube. The other generative nucleus fertilizes the ovum in the usual way.

This is an important variant on the normal embryo-sac structure, but clearly a reduction from it. The exact homologies of the nuclei are obscure. If we consider the embryo-sac of Cypripedium to represent the upper half of the Lilium sac, its four nuclei are truly homologous with the upper tetrad 
in Lilium. The oniy variation in the details of fertilization is that the nucleus of one synergid takes the place of the lower polar nucleus.

This explanation seems likely, for the Orchids have always been considered as highly specialized forms, probably derived from ancestors with flowers of liliaceous symmetry. But if the four-nucleate embryo-sac of Cypripedium really represents the eight-nucleate sac of Lilium the exact origin of each nucleus becomes important. Is the chalazal nucleus sister to the ovum nucleus, or to one of those in the synergidal cells?

These are the major irregularities hitherto described in normally fertilized embryo-sacs. The minor irregularities chiefly concern the antipodal cells. One of these variations may be of some phylogenetic importance. The antipodals occasionally multiply - in some cases forming quite a tissue at the base of the embryo-sac-either before or after fertilization. This character is common in certain groups, as the Gramineae and Compositae. It has been recorded lately among the Gentians (Guérin, 29), as well as in several isolated genera (Guérin, 30, pp. 39-4I) ; and the tissue thus formed may possibly represent the primitive prothallus or female gametophyte.

Considering the vast number of embryo-sacs described, these anomalies are exceedingly few. Indeed, if we exclude all apogamous and parthenogenetic forms, we find the formation of the ovum and of the endosperm to be alike in every genus examined, with the single exception of Peperomia. This is the more surprising, as forms likely to show primitive features have been picked out for examination, and, again excepting Peperomia, they have all proved perfectly normal in essentials. Such are Piper and Heckeria (Johnson, 48), Casuarina (Frye, 26), Carpimus (Benson, Sanday, and Berridge, 10), and Drimys (Strasburger, 86).

In short, the early history of the embryo-sac is wonderfully uniform throughout the Angiosperms. This cannot be attributed merely to the great reduction of the female gametophyte. For the nuclear divisions within the embryo-sac are extremely characteristic in the final orientation of their products. Nor can the uniformity observed be put down to insufficient evidence, for the early history of the embryo-sac has been followed in a great number of species.

The formation of the endosperm is likewise very uniform throughout the group. In every normal case ${ }^{1}$ it is undoubtedly formed after fertilization. Its origin from a nuclear fusion has been observed in numberless instances; indeed there is no normal case to the contrary. The regular occurrence of a triple fusion in which one element is a male nucleus has also been recorded in many cases. The only real exception on record is Peperomia, where, as just stated, more than three nuclei take part in the fusion, and the presence of a male nucleus within it has not been verified.

\footnotetext{
1 By normal case I mean an embryo-sac in which the ovum is normally fertilized.
} 
Thus the comparison of Angiospermous embryo-sacs with each other has given no clue to their primitive structure. What suggestions are offered by Gymnosperms?

Among Gymnosperms, with the exception of Gnetum and perhaps Welwitschia, the mature unfertilized embryo-sac contains archegonia embedded in prothallial tissue. Archegonia are never found in Angiosperms, and we have seen that the exact equivalent of the prothallus cannot be determined. The absence of archegonia from the embryo-sac of Gnetum naturally suggests an approach to Angiospermous structure.

The three genera included in the Gnetaceae differ widely in the structure of their embryo-sac. In Ephedra, undoubtedly the most primitive form, it is completely Gymnospermous ; but certain features in its development both before and after fertilization have suggested to Miss Berridge (11) a new interpretation of the Angiospermous embryo-sac.

The facts on which this hypothesis is based have been lately published by the same author in conjunction with Miss Sanday (12). They are, shortly, as follows. The upper part of the mature embryo-sac in Ephedra distachya is partly divided from the lower region by a constriction in the wall. The tissue which fills it is on the whole looser in texture, more spongy, than that of the lower cavity. But near the apex of this upper region is a 'compact conical mass of archegonia and jacket-cells' (12, p. I29). The initials of archegonia and jacket-cells are alike: they are found as a pyramidal group of tubular alveoli in the young embryo-sac (12, Fig. 3). Each archegonium initial gives rise to the primary neck-cell and the central cell. Within the central cell a nuclear division, apparently amitotic, separates the nucleus of the ovum from the ventral canal nucleus. A ventral canal cell is not formed.

'At the time when the primary neck-cells are being cut off from the initials, the tubular cells between the latter are undergoing a series of divisions, and forming rows of jacket-cells arranged in a regular manner. The likeness of these to the central cells, except in the matter of size, is apparent in Fig. 4.' . . ' This tissue keeps pace with the growth of the central cell, first by cell division, and later by individual growth of the cells. They soon become crowded with food material, and the nucleus divides into two by direct division long before this occurs in the central cells' (12, p. I67).

The jacket-cell nuclei are capable in $E$. distachya of giving rise to apogamous proembryos after fertilization has taken place in the archegonium they enclose. Before fertilization, nuclear fusions are common in the jacketcells. A nucleus from one jacket-cell migrates to another and fuses with a nucleus within it. A nucleus may even migrate from a prothallial cell into an adjacent jacket-cell (11, p. 282). Mitotic figures with twenty-four chromosomes-the sporophytic number-are found within the jacket-cells at this 
period. The fact that an empty cell is commonly found in the neighbourhood of that in which such mitosis is taking place confirms the conclusion naturally drawn from the number of chromosomes that the dividing nucleus is a fusion product. Apogamous proembryos are probably formed from the daughter nuclei of such mitoses.

The apogamous proembryos may be formed in situ; that is, within the jacket-cells to which their primary nuclei belong. In such cases their development rarely proceeds far. But nuclei from the jacket-cells sometimes penetrate the wall which divides them from the central cell of the archegonium, and there is good reason to think that the proembryos found within it are produced by the activity of such escaped nuclei. Such proembryos often develop suspensors, which may even bear rudimentary embryos at their tips $(11$, p. 282). Since they are always formed after fertilization, their production may depend on some stimulus transmitted from the pollen-tube. Miss Berridge even thinks it possible that an escaped jacketnucleus may sometimes fuse with a nucleus from the pollen-tube (11, p. 283).

In Gnetum the archegonium has disappeared altogether. Karsten (50) and Lotsy (55) have shown that a number of equivalent nuclei lie near the apex of the embryo-sac. Each of these seems to be a female nucleus, and in Gn. Gnemon at any rate each pollen-tube which discharges its contents into the embryo-sac fertilizes two of them (Lotsy (55), p. $9^{6}$ and Fig. 45). Before fertilization there is no appearance of cell-formation round these nuclei. The prothallus fills the lower part of the embryo-sac. In Gn. Gnemon it is practically complete before fertilization (Lotsy); but in the species described by Karsten its development is arrested at an early stage, and is not resumed until fertilization of one or more of the apical nuclei has taken place.

Details of the fertilization of Welwitschia are still lacking, but Pearson (64) has described the development of the young embryo-sac very fully, and it is clear that cell-formation is complete in every part of it some time before fertilization. Each archegonium must therefore be represented by one cell at least, not, as in Gnetum, by a single nucleus. As in Gnetum, the apical end of the embryo-sac is clearly differentiated from the lower part.

Miss Berridge suggests that the endosperm in Angiosperms may be comparable to the apogamous proembryos produced within the archegonium of Ephedra distachya by division of nuclei escaped from jacket-cells. Her interpretation of the Angiospermous embryo-sac is best given in her own words :-

'Here therefore we have a process occurring in the embryo-sac of a Gymnospermic genus, which shows a remarkable likeness to the development of the Angiospermic endosperm after triple fusion; that is to say, we have cell-formation resulting from the fusion of nuclei, one of which at least is allied to the egg-nucleus, and taking place under the stimulus due to the entry of the pollen-tube. 
- Moreover, if the polar nucleus is regarded as the homologue of the jacket-initial nucleus, it is possible to trace among the eight nuclei of the Angiosperm embryo-sac representatives of the four classes of cells which we find in the sac of Ephedra and other Gymnosperms.

' 1 . The egg-nucleus in Angiosperms is homologous with the initial nucleus of the archegonium, which, as in Gnetum, matures without the formation of that organ; it therefore represents the latter.

'2. The synergidae probably represent the cells in the upper part of the prothallium, whose only function appears to be the nutritive one common to the whole, but which, as Strasburger suggests, have assumed in Angiosperms a new one in relation to the pollen-tube.

'3. The antipodal nuclei represent the nutritive and haustorial cells which compose the lower part of the prothallium.

'4. The upper polar nucleus represents the jacket-cells, which, though not as a rule capable of fertilization, yet, after union with another nucleus, appear to be in a condition to receive stimulus from the contents of the pollen-tube and to proceed to the formation of proembryos. Since in the Angiosperm embryo-sac there is reduction to one solitary nucleus, the stimulus from the pollen-tube naturally takes the form of fusion with the second male gamete' (11, pp. 283-4).

Certain details in the above scheme are perhaps open to criticism. The synergidae might well be considered to represent two initial cells, comparable with the archegonium initial represented by the ovum, and the jacket-cell initial represented by the upper polar nucleus. The lower polar nucleus is presumably of prothallial nature, like the antipodals, though this is not definitely stated. But these are mere details. Miss Berridge's comparison of the apogamous proembryos of Ephedra with the endosperm of Angiosperms throws a completely new light on this obscure subject, and suggests definite lines of research. Our knowledge of embryo-sac structure and of the details of fertilization in other species of Ephedra is so far very fragmentary. More complete information on these points, and on the corresponding features in Welveitschia, may possibly settle the vexed question of the homology of the endosperm, and at the same time determine the true position of the Gnetaceae in the Natural System.

Comparison with the embryo-sac of Gnetum is of the utmost interest, though at present it can be only tentative. We may suppose that the common ancestor of all branches of the Gnetaceae possessed an embryo-sac in which a group of archegonium initials occupied the apex, and true prothallial tissue the base. Some of these initials may have produced jacket-cells in the mature sac. Whether this were so or not, all the initials might be reduced alike to naked nuclei. Thus in Gn. Gnemon each of the equivalent nuclei in the apex of the sac, supposed by Dr. Lotsy to be all 
equally capable of fertilization, would represent an archegonium initial in some ancestor, more or less remote. As Miss Berridge remarks, this hypothesis fully justifies Dr. Lotsy's assertion that the archegonium in Gnetum is reduced to a naked nucleus, and that reduction has in this respect proceeded further than in Angiosperms, where the ovum is a complete cell (55, p. 103).

At first sight the interruption of prothallial formation by the act of fertilization, as described by Karsten (50) in other species of Gnetum, recalls the Angiospermous history. But there is no real resemblance. When the pollen-tube enters the embryo-sac of Gnetum, the endosperm consists of numerous free nuclei embedded in its parietal cytoplasm. After the epoch of fertilization these nuclei appear to divide ; cell-walls are formed round them ; and development proceeds in the usual way until the embryo$\mathrm{sac}$ is filled with tissue. The homology with the endosperm of other Gymnosperms would be clear even without the link supplied by Lotsy's description of Gnetum Gnemon (55). In the embryo-sac of Angiosperms, however, the whole endosperm begins with the mitosis of a fusion nucleus which contains a male element from the pollen-tube. Thus the endosperm is of necessity developed after fertilization, because the nucleus which gives rise to it is not complete until that epoch. No trace of such a process is found in Gnetum. The primary nucleus of the endosperm is not a fusion product. It has given rise to a number of equivalent nuclei before fertilization occurs, and growth is resumed afterwards by the simultaneous activity of these nuclei, or the greater part of them.

No tissue then in Gnetum, nor, so far as we know, in Welwitschia, can be considered as the direct representative of the Angiospermous endosperm.

To sum up, the germination of the embryo-sac and the history of the endosperm isolate Monocotyledons and Dicotyledons from all other plants. The only adequate explanation of the identity of two processes so complicated in two separate races is inheritance of these features from an ancestor common to both. The alternative explanation is independent evolution of both members along distinct lines of descent, and to attain identity in that way would require a series of coincidences so improbable as to be inconceivable.

The argument from these two features is very much stronger than the similar argument founded on the identity of the carpels in both classes, since the coincidences in structure are more numerous and more striking. The value of both arguments is much increased when they are considered together.

Monocotyledons and Dicotyledons have another member of great importance in common - their flower. But whether a morphologist considers 
the possession of that member to be a character which isolates them from other groups will depend largely on the views he holds on the primitive form of flower.

The subject has been so fully discussed in Messrs. Arber and Parkin's recent paper (4) that I will not treat it at length here. The difficulty arises from the astonishing variety in the floral structure of the Angiosperms. No botanist has yet succeeded in framing a definition of a flower which will include every form among them and yet exclude the reproductive organs of all Gymnosperms and Pteridophytes. The presence of a carpel indeed separates hermaphrodite and female flowers in Angiosperms from the corresponding organs of Gymnosperms and other groups, but male Angiospermous flowers have also to be distinguished from the male cones of other plants. Nor does a definition depending on the presence of a carpel add any weight to the collective argument in favour of a monophyletic origin, since we have already considered that character separately.

Yet in practice it has been found the most convenient plan to confine the term 'flower' to the Angiosperms. Gymnosperms were long ranked among Flowering Plants, but the difficulty of describing their reproductive axes in floral terminology has produced quite a literature on the homologies of the Gymnospermous cone and its parts. This difficulty suggests that there is something unique about the flower of the Angiosperm. What then are its differentiating characters?

The complete flower with its concentric whorls of perianth-leaves, stamens, carpels, really is confined to the Angiosperms. Those botanists who maintain that all other floral forms are modifications of this type, reduced from it, are justified in declaring that a true flower is not found outside the group. On this view all Angiosperms display traces of a complete flower, and the presumption that it was inherited from a common ancestor is then very strong. The antiquity of the complete flower as compared with the simple unisexual type is very strongly supported by Messrs. Arber and Parkin. The subject will be better discussed when we attempt the reconstruction of the Primitive Angiosperm. For the present it is sufficient to say that I agree with this view, and the possession of a true flower is therefore in my opinion a further argument for the monophyletic origin of Angiosperms. But the case in favour of such an origin is already so strong that it is not necessary to insist on corroborative evidence.

\section{Reconstruction of the Primitive Angiosperms.}

In the previous section I have given reasons for believing that Monocotyledons and Dicotyledons are derived from a single stock which was Angiospermous in all its essential features. This race of plants may be called for convenience the Primitive Angiosperms. The term must be 
understood to apply to the immediate ancestors only of our two groups of living Angiosperms.

By the kindness of the authors, I am able to reproduce here the Table of Relationships given by Messrs. Arber and Parkin on p. 77 of their memoir :-

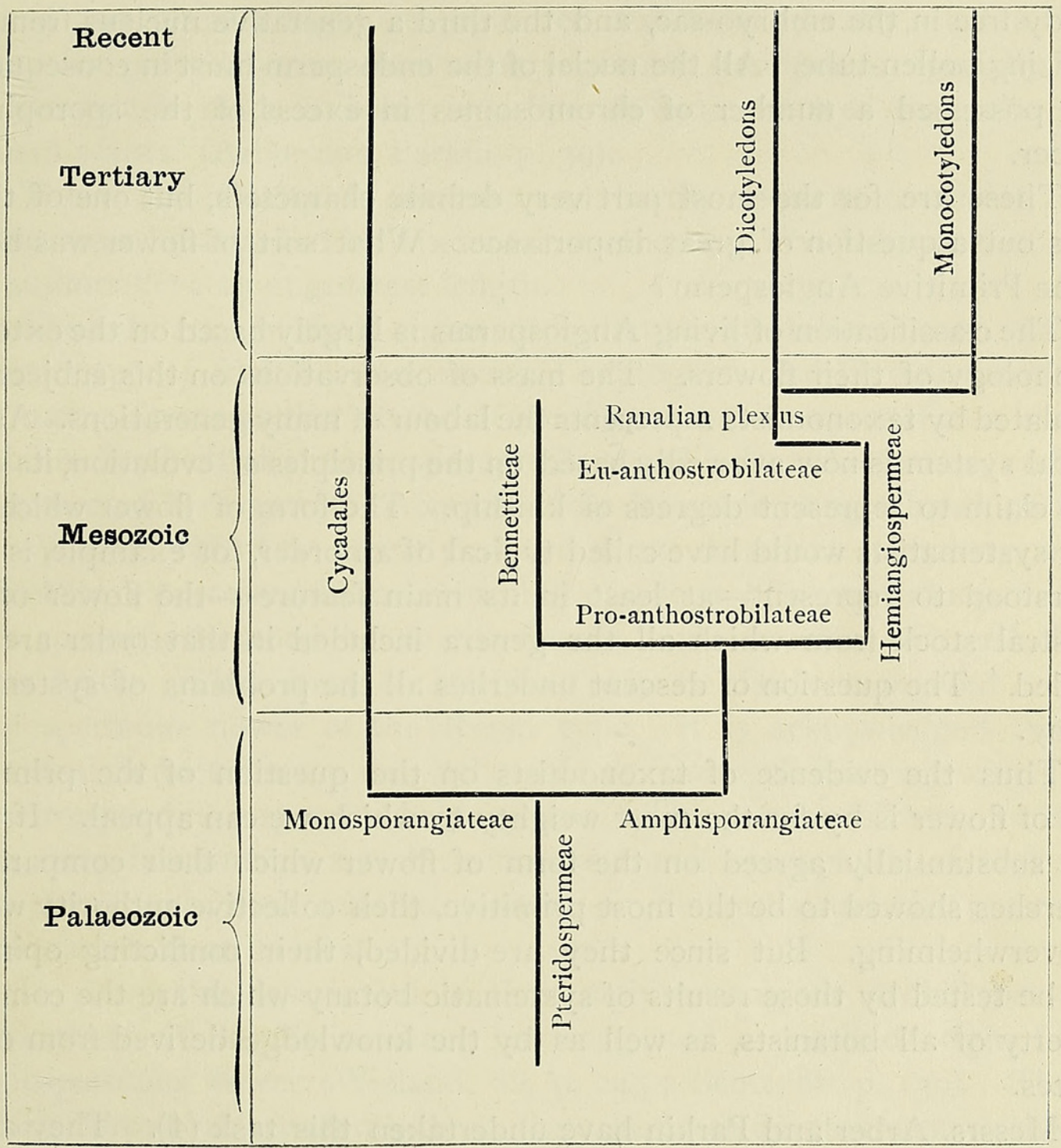

In referring to this skeleton pedigree, I do not mean to attach more importance to the views it represents than do the authors themselves. They clearly regard it as a provisional statement, which will probably require amendment in the light of future research. But the merit of such graphic statements is to suggest that historical perspective which it is so difficult to preserve in dealing with phylogenetic problems.

In this Table the Primitive Angiosperms, defined as above, would stand in the main line of descent, just below the junction of Monocotyledons with Dicotyledons. We are entitled to assume that they possessed all those characters which are common to Monocotyledons and Dicotyledons. The 
foliage of the leafy plant was Angiospermous : it bore flowers and seeds : its ovules were enclosed in carpels. The male gametophyte was represented by three nuclei within the pollen-tube. The female gametophyte before fertilization consisted of six cells and two free nuclei, orientated in a very characteristic way within the embryo-sac. The endosperm was formed after fertilization and arose from a fusion of three nuclei-two of them already free in the embryo-sac, and the third a generative nucleus from the fertilizing pollen-tube. All the nuclei of the endosperm must in consequence have possessed a number of chromosomes in excess of the sporophytic number.

These are for the most part very definite characters, but one of them opens out a question of great importance. What sort of flower was borne by the Primitive Angiosperm?

The classification of living Angiosperms is largely based on the external morphology of their flowers. The mass of observations on this subject accumulated by taxonomists represents the labour of many generations. As the natural system is now avowedly based on the principles of evolution, its divisions claim to represent degrees of kinship. The form of flower which the elder systematists would have called typical of an order, for example, is now understood to represent-at least in its main features-the flower of the ancestral stock from which all the genera included in that order are descended. The question of descent underlies all the problems of systematic botany.

Thus the evidence of taxonomists on the question of the primitive form of flower is by far the most weighty to which we can appeal. If they were substantially agreed on the form of flower which their comparative researches showed to be the most primitive, their collective authority would be overwhelming. But since they are divided, their conflicting opinions may be tested by those results of systematic botany which are the common property of all botanists, as well as by the knowledge derived from other sources.

Messrs. Arber and Parkin have undertaken this task (4). They agree with the elder systematists who considered the primitive flower as an elaborate structure, its numerous tepals, stamens, and carpels arranged spirally on the axis in acropetal succession. Such flowers occur in living species-for example in the Magnolia and other members of the Ranales. According to this view, all other floral types are derived by reduction from this.

The alternative view is held by most modern taxonomists, but not by all (Arber and Parkin, pp. $3^{8}, 39$ ). It is agreed that a large numberperhaps the majority - of simple unisexual flowers are derived by reduction from more complex bisexual forms. But these complex floral types are supposed to be themselves built up from unisexual ancestors, and some 
living forms which represent such ancestors are considered as the most primitive flowers known.

Three objections are raised against this view. 'In the first place it must be assumed that the perianth is evolved de novo, and is an organ sui generis. Secondly, in many of the groups regarded as primitive, e.g. Peperales, Amentiferae, and Pandanales, the inflorescence is a sharply defined and often a highly complicated structure. Lastly, such a theory has so far proved barren from a phylogenetic standpoint, especially when the attempt is made to bring into line evidence derived from the study of fossil plants' (Arber and Parkin, p. 39).

The first difficulty is obvious and hardly requires comment. The second must be attacked by taxonomic methods. The third is that which the authors develop at greatest length.

The substance of their argument is that the strobilus or cone is a very ancient type of fructification among Cryptogams and Gymnosperms, and that such a flower as that of the Magnolia can be interpreted as a bisexual strobilus in which the male sporophylls stand below the female, and both are protected by a special series of sterile leaves forming a basal perianth. Dr. Wieland (89) has recently shown that American members of the Bennettiteae possessed bisexual strobili of a form hitherto unknown. The male sporophylls stood below the female, and a number of sterile leaves below both. This form of strobilus may be fairly compared with an Angiospermous flower of the Ranal type. It is acknowledged that the individual Bennettitean sporophyll, male or female, differs very widely from the corresponding organ in Angiosperms. The points which the fructifications have in common are the arrangement of sporophylls of both sexes on a single axis, their relative position on that axis, and the presence of sterile members at its base.

In short, the description of the amphisporangiate strobili belonging to members of the Bennettiteae has suggested a possible origin for the Angiospermous flower (Wieland, 89, p. 245 ; Scott, 80, p. I39). There is nothing forced or unnatural about the scheme of development worked out in detail by Messrs. Arber and Parkin. But any such scheme requires that the more recent ancestors of our living Angiosperms should have borne flowers of the anthostrobiloid type, that is, flowers in which perianth leaves, stamens and carpels are arranged on the axis in acropetal succession. Such flowers are actually found among living Angiosperms. They have been considered primitive on taxonomic grounds by many authorities in the past, and are still thought to be so by some modern botanists. Their claims to antiquity are certainly much strengthened by the resemblance lately discovered between certain of their features and the corresponding features in extinct forms with Gymnospermous seeds.

It may perhaps be objected that the resemblance is superficial. Why 
should so much stress be laid on the position of female above male sporophylls, and on the presence of sterile members at the base of the cone?

There is, I believe, no exception to the rule that in every hermaphrodite flower the carpels stand above the stamens. Because the arrangement is universal we are in danger of supposing it inevitable. But it would be difficult to find a physiological cause for this sequence which would apply to every case without exception. Indeed, in certain inflorescences which for all physiological purposes are equivalent to hermaphrodite flowers, the carpels stand below the stamens (Arum, \&c.). This shows that such an arrangement may under certain circumstances benefit the plant.

In some heterosporous cones (e.g. Lepidostrobus Hibbertianus, quoted by Messrs. Arber and Parkin, 4, p. $3^{8}$ ), the microsporophylls stand above the megasporophylls. The Angiospermous sequence is clearly not physiologically inevitable either in flowers or cones. The Bennettitean strobilus is said to stand alone among strobili in the sequence of its parts combined with the possession of a whorl of sterile members at its base (p. 37). This unique combination of characters finds a parallel in the Angiospermous flower.

The strobiloid theory of the flower seems in the present state of our knowledge to stand alone as a working hypothesis. If we reject it, we are left without any historical clue to the origin of the floral structure of Angiosperms. If we accept it, the Primitive Angiosperm must be credited with a flower resembling that of Magnolia or Liriodendron in general plan.

The Primitive Angiosperms have now been invested with certain characters which are common to Monocotyledons and Dicotyledons. Nobody who admits the existence of a single group of Primitive Angiosperms will question their right to these. The vexed question of their floral structure has been summed up in favour of the Ranal type on the grounds given by Messrs. Arber and Parkin. The characters in which Monocotyledons differ from Dicotyledons have not yet been discussed.

The two characters which separate Monocotyledons from Dicotyledons most completely are (I) the anatomy of the mature stem, and (2) the number of cotyledons. Less constant points of difference are found in the leaf and root structure, and in the floral symmetry.

The question before us is whether the Primitive Angiosperms resembled one class or the other in these respects, or were completely different from either. This third suggestion is unlikely; in all probability the Primitive Angiosperms resembled one branch of their descendants or the other in each of the characters in which those classes differ, but it is quite possible that they possessed some characters which we now call Monocotyledonous together with others which are proper to Dicotyledons. The evidence concerning each character must be considered on its own merits. 
Before proceeding to the examination of this evidence, it should be mentioned that the controversy is a very old one. Botanists have discussed the comparative antiquity of Monocotyledons and Dicotyledons for several generations. For a long time the prevalent opinion was that Monocotyledons were older than Dicotyledons-in other words, that Primitive Angiosperms resembled modern Monocotyledons in the characters in which they differ from Dicotyledons.

Evidence in favour of this opinion was derived from three sources: the succession of fossil forms, the comparative anatomy of the stem, and the development of the embryo within the embryo-sac.

The fossil argument was founded on a mistake. It is now generally acknowledged that Monocotyledons do not appear before Dicotyledons. On the contrary, they are found together in the earliest beds in which Angiosperms appear at all (Seward, 80. $a$; Zeiller, 91, pp. 2I9-2I). The arguments from stem anatomy and embryology will be considered under those heads.

\section{STEM-STRUCTURE.}

As Primitive Angiosperms have not yet been identified in the fossil state, there is no direct evidence concerning their stem-structure.

The features common to the stems of Monocotyledons and Dicotyledons are three. Their vascular skeleton is built up in the first instance of leaf-traces only. Each leaf-trace while young is collateral in structure. The xylem of each leaf-trace is endarch. We may assume that the stem of Primitive Angiosperms possessed these characters.

The leaf-traces of the typical Dicotyledonous stem are arranged in a single circle. In each trace the xylem is internal and the phloem external, and they are divided from each other by a meristematic layer, the cambium. At first the cambium is not found outside the traces, but it soon forms a continuous cylinder within the stem, which produces secondary phloem on the outside and secondary xylem on the inside. The stem now in place of isolated leaf-traces displays a series of three concentric cylinders : centrifugal xylem, centripetal phloem, and meristematic cambium between them.

In the great majority of Monocotyledons no thickening-ring of any kind is formed. The numerous leaf-traces are scattered over the transverse section of the stem with apparent irregularity. Their origin from leaves with a more or less definite phyllotaxy leads to a primary arrangement in concentric circles, and each leaf-trace as it enters the stem is orientated with internal xylem and external phloem. At this level it is collateral in structure, as in the leaf itself. There is no layer of meristematic tissue within the bundle, consequently secondary elements are never added to it. 
The leaf-traces of a Monocotyledon do not run parallel to the axis of the stem throughout their course, and the original arrangement in concentric circles is soon lost. Torsion of the trace on itself leads to irreguiar orientation, and even the collateral structure sometimes becomes concentric. The type of bundle called by Professor Jeffrey amphivasal $\left(46, p .3^{I}\right)$ is so common in the older stems that he figures it as the typical Monocotyledonous bundle (loc. cit., Fig. I I $3, H, H$ ). In this form of concentric bundle the phloem is completely surrounded by xylem. Professor Quéva points out that in the stem of Gloriosa concentric bundles are due to anastomoses of collateral traces with each other $(65$, p. 87 and Figs. 125 , 126). This is certainly the case in the scutellum of Zea Maïs (Sargant and Robertson, 74, p. I2I and Figs. I5-I8). In the lower part, where branches are absent, the main bundle is collateral. But in the upper part, where branches are inserted all round the main bundle, it becomes almost amphivasal.

Thickening-rings are formed in the cortical parenchyma of certain Monocotyledonous trees, but they do not constitute a cambium in the Dicotyledonous sense.

The numerous differences in detail which separate the stem-structure of Monocotyledons from that of Dicotyledons depend more or less directly on the presence or absence of an active cambium. Its presence secures a single ring of leaf-traces, the persistence of their collateral structure, and their uniform orientation. This is illustrated by the structure of Dicotyledons in which the cambium has become inactive and is disappearing. In such forms we find not only the scattered arrangement of the traces (Holm on Podophyllum, 45, pp. 429-30. Cf. also Fig. 10 on p. 52 of Solereder, 81), but even occasional amphivasal structure (Worsdell, 90, p. 600). It was a true instinct which led early botanists to lay so much stress on the presence of a cambium. The character it affords is also one of the most satisfactory to taxonomists, for, though some Dicotyledons have lost the cambium, it is not found as a really active tissue in any Monocotyledonous stem.

The question really is, then, whether the Primitive Angiosperms possessed a cambium. Evidence of two kinds is available : comparison of the Angiospermous stem with that of Gymnosperms and Cryptogams, and comparison of the mature stem of Monocotyledons and Dicotyledons respectively with the seedling stem of the same class.

A cambium is the rule among living Gymnosperms, and universal among the extinct forms yet investigated. Traces of its existence are very rarely found among living Vascular Cryptogams (e.g., see Cormack, 17). The absence of a cambium was formerly considered as a conclusive mark 
of the low place in the botanical scale held by Vascular Cryptogams. For many years fossil botanists were accustomed to place all the stems with normal secondary thickening among Phanerogams without further question. While this view prevailed, the absence of cambium in the stems of Monocotyledons was naturally considered as a primitive character. Now, however, a cambium is known to be the rule among the extinct Vascular Cryptogams whose tissues have been sufficiently well preserved for microscopic examination. The marked difference between living and extinct forms in this respect is no doubt due to the fact that living Vascular Cryptogams are herbaceous, while the forms preserved as fossils are mainly trees. In such forms a cambium would be found if it existed within the group at all.

The evidence then shows that a cambium is much more ancient than the Primitive Angiosperms, and that they probably inherited one, from whatever race of Gymnosperms or Vascular Cryptogams they descended.

Comparison of seedling with mature Dicotyledons shows that the ring of leaf-traces is visible in the plumule so soon as vascular tissue is differentiated within it. Cambium is present from the first within each trace, and appears between them very shortly. The single ring of open bundles is formed even in the seedlings of such forms as Podophyllum, in which the later bundles are closed and scattered within the stem.

Thus the primary stem-structure of Dicotyledons is the same in the seedling as in the mature plant. If the Monocotyledonous type were primitive, we might expect some of its features to appear in the young Dicotyledon. Amphivasal closed bundles should be formed first, and pass gradually into the open collateral form. But this does not happen. The earliest bundles formed are collateral, and have a well-marked cambium.

Among Monocotyledons, on the other hand, the characteristic stemstructure is reached only when the stem approaches maturity. The bundles of the seedling internodes are collateral, and frequently contain traces of a cambium. Their arrangement within the stem can be traced satisfactorily only in the rather exceptional forms in which the early internodes are well developed. In such forms Professor Jeffrey (46, pp. 3I4, 3I5) has pointed out that the bundles of the first internodes are commonly arranged in a single circle, and orientated as in Dicotyledons. It is true that, while there are still very few leaves, their traces would naturally fall into a single circle. But their regular orientation in that circle-xylem inwards, phloem outwards-suggests that they were formerly linked together by a cambium. Besides, the occasional presence of a short-lived cambium within the traces of the seedling, and their strictly collateral structure, are very strong evidence for supposing that to be the primitive structure of the leaf-trace instead 
of the closed type, which is universal in the mature Monocotyledon, or the amphivasal form which is characteristic of it.

Traces of a cambium in the vascular bundles of Monocotyledonous seedlings have been recorded by several observers. Miss Anderssohn (1) in 1887 figured a cambium within the bundles of seedlings belonging to thirteen species. The tissue is clear in all her figures: it would seem best marked in Zea, Typha, Lilium, and Dracaena. Among my own preparations there are ten well-marked instances from eight genera. I found the greatest development of cambium in the hypocotyl of Yucca arborescens. It is quite clear in the same region of two other species in that genus, $Y$. gloriosa and $Y$. aloifolia. Cambium appears also in cotyledonary bundles of Milla, Dipcadi, Galtonia, Albuca, and Fritillaria. Elettaria and Musa show it in the traces of the first and second leaves.

The cambium in all these forms is very transient. It is not seen in the very young bundle, where the protoxylem is only just lignified. Such a bundle is often wedge-shaped in transverse section. The lignified protoxylem is at the sharp angle of the wedge, a group of sclerenchyma at the broad end, and just within the sclerenchyma a few elements of 'soft bast'. Between protoxylem and protophloem is an ill-defined region, of which the elements bordering on the protoxylem will become metaxylem, and those adjacent to the protophloem will form more phloem. Before this process is complete, three or more rows of cells between phloem and xylem will often be found in radial series. The innermost rows will be added to the metaxylem, the outermost to the phloem. Divisions in this region soon cease, and alterations of shape and size-perhaps a few irregular divisions too-in the elements added to the bundle usually destroy the original radial sequence. When this has disappeared, no trace is left of the formation of cambium.

Professor Quéva has worked out the anatomy of Gloriosa superba, a tropical Liliaceous climber, from germination to maturity (65). The plant produces fresh aerial stems every year. They die down at the end of each growing season. The perennial organ is a V-shaped tuber, which is simply a branched and thickened segment of the stem. The tuber lasts through two seasons. In the first it is formed on the parent tuber and grows to its full size. In the second it renews its growth, giving rise to two aerial stems and two new tubers. This activity exhausts the food laid up in the first year, and brings about the death of the tuber.

The bundles of the seedling stem possess a short-lived cambium, which adds phloem and xylem elements to the complete structure (Quéva, p. I02). Traces of its activity are soon obliterated by subsequent divisions in the secondary elements, and by irregularities of growth which destroy their original arrangement in rows. The bundles of the stem-segment which becomes the tuber of the seedling plant have lost all traces of 
this early cambium, and secondary growth is never resumed in this tuber.

The bundles of the second tuber, however-that which springs from the tuber of the seedling-possess cambium which is particularly active in the second season. Professor Quéva figures the radial rows of elements added to phloem and xylem (65, Figs. 72 and 90). He does not describe the formation of intrafascicular cambium at any time.

All succeeding tubers show a similar formation of secondary tissue, more massive than in the second tuber (p. 56, and p. $5^{8}$ ).

The presence of a functional cambium in the mature bundles of a Monocotyledon may be advanced to show that they are derived from an ancestor which possessed one. Professor Quéva takes this view:-

- The persistence of a cambial zone in the bundles of certain Monocotyledons shows that we may logically consider them as derived from the more primitive Dicotyledons by means of the early disappearance of the cambium, and an increase in the number of traces from each leaf.' (Translated from 65 , p. I47.)

Comparison of seedling anatomy in the two classes, then, leads to the conclusion that the dicotyledonous stem-structure is primitive, the monocotyledonous derived from it. This conclusion agrees with that founded on comparison of the mature stem anatomy in both classes with that of other groups, living and extinct. The presence of a cambium is the rule, its absence the exception. Except in Gloriosa, it is completely lost in the mature stem of Monocotyledons, but it can still be found occasionally in the traces of their seedlings.

The Primitive Angiosperms, then, must be credited with a cambium, which has been very completely lost by one branch of their descendants.

\section{Number of CoTYledons.}

Monocotyledons differ from Dicotyledons in other mature characters besides the structure of their stems. But these are far less constant, and may be considered later. An embryonic character - the difference in the number of cotyledons - must come first, for in systematic importance it ranks with the stem anatomy, or even takes place of it.

No Monocotyledon with which I am acquainted has two cotyledons. Some Dicotyledons, indeed, have only one. The species with this abnormal feature are widely separated in the Natural System. They belong to the Ranunculaceae, Fumariaceae, Umbelliferae, Primulaceae, Lentibulariaceae, Nyctaginaceae (72, p. 76). Perhaps the species of Peperomia lately described by Mr. A. W. Hill also belongs to this list (39). Altogether I cannot find quite twenty species of Dicotyledons in which this character has been recorded. The possession of one cotyledon then is universal among Monocotyledons, and the possession of two very nearly so among Dicotyledons. 
The question is whether Primitive Angiosperms had one cotyledon or two. Evidence of two kinds is available. Living Angiosperms may be compared with other groups. If the number of cotyledons found among lower plants, living or extinct, be at all constant, there would be some reason to suppose that number to be derived by Primitive Angiosperms from their ancestors.

In the second place, there is embryological evidence. The development of the embryo in both classes may perhaps repeat its race-history in some degree. Many observations have been made on the development of the embryo within the embryo-sac, that is, on the period in the history of the young plant which begins with the division of the fertilized ovum and ends with the formation of the ripe seed. The next period commonly begins with germination. The embryo of the ripe seed has merely to elongate its members and push them out of the seed-coats in order to become the seedling.

But this is not always so. In a considerable number of species belonging to both classes, but particularly numerous among Monocotyledons, the embryo passes through a period of maturation between the ripening of the seed and its germination. In such species the embryo is not ready for germination by the time the seed is ripe ; it resumes its growth within the embryo-sac when sown under proper conditions. Seeds containing such embryos lie dormant in the soil for months after they have ripened and been shed from the plant. Germination is of necessity postponed until the embryo is fully differentiated.

For our present purpose, however, the epoch of germination is the most convenient division. The embryological evidence will be considered under two heads : the development of the embryo within the embryo-sac, whether that development is complete within the ripe seed or not, and the development of the seedling after germination.

Let us begin by comparing Angiospermous cotyledons with those of other plants. The Gymnosperms alone possess cotyledons which are clearly equivalent to them. Among Gymnosperms two cotyledons are found in the Cycads, in the Gnetaceae, in the extinct Bennettiteae, in Gingko, the Cupressineae, and the Taxaceae. More than two are found among most Abietineae and Taxodineae. The Araucarieae differ. Agathis has two cotyledons, Araucaria two to four.

Two cotyledons, then, are very frequently found among Gymnosperms. One is unknown, unless it occur in Ceratozamia. ${ }^{1}$ The more primitive forms, such as the Cycads and Ginkgo, have two. So have the Gnetaceae and Bennettiteae, two groups which in other characters approach Angiosperms. With the exception of the poly-cotyledonous Araucarias, those groups which 
possess more than two cotyledons have little claim to be regarded as primitive on other grounds. Moreover, there is some reason to think that where more than two cotyledons are present they have been formed by the splitting of an original pair (Hill and de Fraine, 42 ; p. 473).

Comparison with Gymnosperms is thus-so far as it goes-in favour of the assumption that two cotyledons were transmitted to Primitive Angiosperms by their ancestors.

\section{Embryology within the Embryo-sac.}

The embryological evidence is divided, as already explained, under two heads. We will begin with the development of the embryo within the embryo-sac.

The development of Capsella among Dicotyledons, and of Alisma among Monocotyledons, is described and figured in all textbooks. The figures are commonly reproduced from Hanstein's memoir of 1870 (35). Hanstein himself described several variants on the course of events which he considered typical, and later research has brought others to light. The great majority of Dicotyledons hitherto investigated do not, however, differ much from Capsella. More variation seems to occur among Monocotyledons.

In Alisma and Capsella the cotyledons are the first permanent organs formed in the pro-embryo. The growing-points of root and stem appear later. This is the regular order of development in Monocotyledons and Dicotyledons alike. Leaving such abnormal forms as Cuscuta (Koch, 51) out of the question, the only exceptions with which I am acquainted are found among the Papaveraceae. In Roemeria refracta, figured by Hanstein (35, Pl. VII, Figs. 6 and 8), the growing-point of the stem is indicated almost as soon as the rudiments of the cotyledons. Hegelmaier has shown that in Hypecoum procumbens the stem-apex appears at the same time as the cotyledons, or even a little before them (37, P1. III, Figs. 23-6).

The free end of the embryo increases in size in both types. In Capsella it bifurcates to form the two cotyledons: in Alisma the whole is transformed into a single cotyledon. The growing-point of the root appears at the other end of the embryo, separating it from the suspensor. It is alike in both types. The growing-point of the stem appears between the cotyledons in Capsella, but at one side of the pro-embryo in Alisma-just below the single cotyledon.

To avoid error in the interpretation of these results, the goal must be constantly kept in view. The question before us is whether the Primitive Angiosperms possessed one cotyledon or two. Can the facts just rehearsed be used as evidence on either side?

The simplest interpretation is certainly that the single rudiment found in both classes remains undivided in Monocotyledons, but divides in 
Dicotyledons. This hypothesis was readily accepted by observers already convinced on independent grounds that Monocotyledons were the elder race. Now that these grounds are given up, the embryological evidence stands alone and must be criticized on its own merits.

The chief difficulty in the way of accepting this solution is that the cotyledon of Alisma, for example, is to all appearance a terminal structure. If this represents the ancestral form, the two cotyledons of Capsella must be considered as due to fission of a terminal member. But the typical leaf is formed laterally on the growing-point of an axis. The rest of the growing-point forms other lateral members, at the same time reproducing itself. Can a member formed from the whole of the growing-point-that is, terminally to an axis which then ceases to form new members-be a true leaf?

Many morphologists think that it cannot. If we consider the proembryo to possess an axis, there is no denying that the single rudimentary cotyledon of Monocotyledons, or the bifid rudiment which represents the pair in Dicotyledons, is for a time apparently terminal. Hence some botanists maintain that the cotyledons cannot be considered as true leaves.

Those who hold this opinion belong to two schools. The first draws a distinction between Monocotyledons and Dicotyledons. The cotyledons of the latter may be regarded as lateral members. The apparently terminal position of the rudiment from which they are derived is due simply to the arrest of the growing-point. Though commonly formed later than the cotyledons, it is terminal from the first. Forms such as Hypecoum, in which the growing-point appears at the same time as the cotyledons, or earlier, represent the primitive arrangement. The single cotyledon of Monocotyledons is, however, truly terminal, and cannot be treated as homologous with one or both cotyledons in Dicotyledons. It is an organ sui generis, and can never under any circumstances be considered as a leaf. Its leaf-like appearance in some seedlings is due to homoplastic adaptation (Balfour, 8, pp. 827-8 ; cf. also Coulter and Chamberlain, 19, p. 208).

We need not consider this hypothesis at greater length, since it is hardly compatible with the monophyletic origin of Angiosperms. Indeed its supporters commonly assume a polyphyletic origin.

The second school is represented among recent writers by Professor H. L. Lyon $(57,58)$. He considers the single cotyledon of Monocotyledons as truly terminal, and both cotyledons of Dicotyledons as derived from it by fission. This hypothesis he has carried out to its logical consequences. His views are founded on the structure of the embryo in Nelumbium. He has shown that in $N$. luteum the embryo has no suspensor, and becomes a large, undifferentiated, nearly spherical mass before the cotyledons are indicated. They appear as a crescent-shaped ridge, which 
soon becomes bi-lobed, and then gives rise to a pair of very long cotyledons (56).

Here there are three variations on the Capsella scheme: the absence of a suspensor, the size of the undifferentiated embryo, and the first appearance of the cotyledons as a single crescent rather than as two distinct rudiments. Of these anomalies, the last is the most important. Many instances are recorded of embryos without a suspensor. It is not very uncommon to find an embryo which attains considerable size before the cotyledons are indicated. Hegelmaier figures an undifferentiated embryo of unusual size in Helleborus foetidus (37, P1. II, Fig. I9), and Johnson describes a similar case in Heckeria (48, pp. 328-9 and Fig. 29).

Professor Lyon considers that in Nehmbium we can trace the development of two cotyledons from a single terminal member, which is derived from a similar member in the embryo of the Primitive Angiosperms and is homologous with the single cotyledon of Monocotyledons. He faces all the consequences of this hypothesis. The ancestral member, being terminal, is not a phyllome but an organ sui generis - perhaps derived from the foot of Vascular Cryptogams, and homologous with the sucker in seedlings of Gnetum and Welwitschia (Bower, 13, 14). The derivatives of such a structure have, of course, no claim to be considered as true leaves. Hence the leaf-like structure of the cotyledons in most Dicotyledons and some Monocotyledons must on this view be attributed to their adaptation to the functions of leaves.

Comparison of the anatomical structure of green cotyledons with that of true leaves shows a remarkable resemblance between them. Professor Ramaley's descriptions, for example $(66,67)$, show identical structure in epidermis, stomata, palisade and spongy tissue, and in the details of the vascular bundle. The differences on which he insists appear to me of minor importance. There are differences in the distribution of stomata, in the number of rows of palisade cells, in the distribution of the bundles.

Schlickum (77), after careful comparison of the cotyledon with the first leaf in a number of Monocotyledons, came to the conclusion that they were homologous with each other. I am confirmed in the same opinion by examination of a series of preparations most kindly made for me by my friend Miss Berridge. She has mounted sections from the cotyledon and first leaf of various Dicotyledons, side by side, and the resemblance in structure is very clear.

In short, to deny that cotyledons are homologous with leaves introduces new difficulties into a subject already sufficiently obscure. Such difficulties are the logical consequences of the three assumptions on which Professor Lyon's theory is based: that the single cotyledon of Monocotyledons is terminal, that a terminal member cannot be a leaf, and that both cotyledons 
of the Dicotyledonous embryo are derived from the single terminal cotyledon of the Primitive Angiosperms by fission.

Two ways of escape are open. We may accept the possibility of a terminal leaf, or we may try to show that the apparently terminal cotyledon is derived from a lateral member.

To begin with the question whether a leaf can be truly terminal. Some botanists attempt to solve the problem by saying that the cotyledon is an active organ of the embryo and assumes the position best suited to its work. That statement is no doubt very true, but it leaves the morphological question untouched. When a member assumes new functions, its structure is of course modified in the course of generations to suit those functions. But modification of a member already fairly well developed rarely goes so far that no trace of its original structure remains either in the embryonic or the mature condition. If such complete metamorphosis were usual, there would be no science of comparative morphology at all.

When a morphologist says that a leaf is essentially a lateral member, he is stating a wide generalization in the form of a law. Experience shows that leaves and leaf-like members are arranged laterally on an axis, which increases in length by means of a terminal growing-point. The rudimentary leaf appears as a lateral out-growth of this terminal meristem.

This statement is undoubtedly justified as a generalization, for instances of leaf-like members not clearly lateral in formation are very rare. Where an axis is present and the whole of its terminal growing-point is converted into a single member, there is a very strong presumption against that member as a leaf. The burden of proof rests with those who assert it to be so.

The cotyledon of Alisma, however, hardly comes under this rule. As Hanstein pointed out in 1870 , neither axis nor growing-point is present when it is formed $(35$, p. 40 , pp. 58-61, pp. 90-98). The pro-embryo is meristematic throughout, and is undifferentiated except for the external distinction between suspensor and embryo proper. The direction of the future axis is first indicated by the formation of a plerome cylinder. As a rule, no specialized growing-point is formed for some time afterwards.

The independent results of Hegelmaier (36) and Fleischer (25) showed in 1874 that the projection of tissue called by Hanstein the stem-apex is in some Monocotyledons the first leaf. The second is developed directly from a region near the base of the first, the third from the second, and it is sometimes a long time before a rudiment appears which becomes the apex of a true axis. In fact, for some time in such an embryo each successive leaf is terminal in the same sense as the cotyledon. When the rudimentary axis of such an embryo does appear, it is apparently a lateral outgrowth from the base of the last formed leaf. By degrees, as the axis becomes better defined, its growing-point assumes a terminal position, and the succeeding 
leaves appear lateral. Are we therefore to conclude that the first two or three leaves in Sparganium (36, pp. 648-52) and the first seven or eight in Pistia (56, pp. 692-3) are really cauline structures which have become undistinguishable from true leaves in response to the demands of the environment, while the succeeding leaves alone have a morphological right to the name?

Those who shrink from this conclusion are faced by two alternatives. They must suppose either that the leaves are only apparently terminal through suppression of the axis, or-with Celakovsky (16)-that leaves were originally terminal members, that the stem began as a symposium of leaf-bases, and that this primitive construction survives only in the embryo and young seedling of a few Monocotyledons. The gradual transition from the terminal to the lateral position, which can be traced in the successive leaves of such forms, would then reproduce a similar transition in the history of the race.

The species which on this view are most primitive among living Angiosperms are, of course, those in which most terminal leaves are formed before the appearance of an axis. In Hegelmaier's researches Sparganium was found to have two or three terminal leaves, Pistia seven or eight. Both are aquatic forms. Pistia is very highly specialized to that habit. The seed before germination remains under water, but soon after germination begins it floats up to the surface, and further development proceeds there. The embryo of Pistia is much reduced : neither a suspensor nor a primary root is formed.

Fleischer's best examples are Funcus glaucus, a semi-aquatic form, and Luzula multiflora, an Alpine species.

My own experience is that the reduction in structure so characteristic of aquatic species is very strongly marked in their young seedlings. For this reason I have rarely found such seedlings of much use in my own work. Ancestral features have commonly disappeared or become obscure in the general loss of differentiation. Thus the fact that terminal leaves seem characteristic of aquatic embryos suggests very strongly that their peculiar position is due rather to suppression of the axis than to any reminiscence of a stemless period in the history of the race.

If we adopt this view, the complete suppression of the axis in the embryo and seedling of Pistia, for example, must be due to adaptation of the embryo itself to its surroundings. If the absence of an axis were a mature character which had become embryonic in the course of evolution, we should expect traces of a stem in the embryo which would disappear in the mature plant. But the converse is the case. The stem exists in the mature plant, and is absent in the embryo and seedling.

In the case of Pistia the conditions of germination are peculiar, and will account for very great adaptations in seedling structure. But less is 
known of the conditions under which the seeds of Sparganium, Funcus, and Luzula germinate, and therefore no precise estimate can be given of the extent to which they might affect the structure of the embryo. All that can be said is that considerable reduction of structure commonly occurs in the embryo and seedling of aquatic and semi-aquatic plants.

The stem-axis of bulbous Monocotyledons is often all but suppressed in the embryo and seedling. Fleischer figures and describes the embryo of Leucojum aestivum. When two leaves are present within the cotyledonary sheath, the stem-apex which was between them is represented only by a limited region of actual cell-division. My own preparations furnish many instances of extreme suppression of the stem in the seedlings of leafy bulbs-Allium, Fritillaria, Galtonia, for example. In such seedlings the stem is often more reduced as compared with the leaves than it is in the mature plant.

The fact that reduction has proceeded further in the seedling than in the mature plant admits of two explanations. It may be said that the absence of stem is a primitive feature, and therefore better marked in the young plant, according to the law of recapitulation. If this were the true explanation we should expect reduction of this sort to be most marked in species which on other grounds appear primitive. But this is not so. It is most clearly seen in aquatic forms and in Alpine or bulbous formsall highly specialized types.

If this explanation be rejected, the alternative is to suppose that in these exceptional forms the causes which result in suppression of the stemaxis operate more powerfully on the seedling than on the mature plant. In many of the instances quoted, this can be shown to be true. The seeds of aquatics, for example, commonly germinate under water, and thus the seedling is completely submerged, to begin with. It leads a more completely aquatic life in many cases than the adult plant which is only partially submerged (Sparganium). Extreme reduction in all non-essential parts is essential in the seedling of Pistia, which has to become light enough to float up to the surface.

The reduction of the seedling in Alpine and bulbous plants is due to other causes. For a full discussion of these I must refer to previous papers (Sargant, 72, pp. 78-8I, and 73, pp. 334-5). The essential point is that a seedling germinating in the short summer of an Alpine summit is faced with a task almost beyond its powers. If it is to survive the coming winter, the seedling must be safely buried in the ground by the end of the summer, and be provided also with a reserve-fund of food. The stem of such a seedling is commonly developed as a tuber in which food is stored. It rarely develops internodes in the first years of its life. Bulbous plants bear traces of evolution under conditions equally stringent, though many of them have to resist hot drought rather than cold in the dead season. 
More time has been spent on the structure of Monocotyledons in which the early leaves appear terminal than such exceptional forms would deserve, were it not for the light which their structure throws on the normal formation of an apparently terminal cotyledon. If there is reason to think that the influence of environment can effect a change in the configuration of the embryo and seedling so complete that the early leaves appear terminal owing to suppression of the stem, equally stringent conditions may account for the formation of an apparently terminal cotyledon.

What are the conditions under which the embryo is formed within the embryo-sac? In general it may be considered as a mass of meristem developing in a confined space, feeding parasitically on the tissues of the mother-plant, and obliged to prepare for a period of rest followed by one of rapid growth and severe competition.

The more obvious conditions which will affect the form of the embryo while it is developing within the embryo-sac are:

I. The space at its disposal, depending partly on the shape of the embryo-sac, and partly on the development and texture of the endosperm.

2. The method of food-supply.

3. The configuration of the mature embryo-that is, of the embryo immediately before its exit from the seed. This again depends on two sets of conditions: the future form of the seedling, which is largely determined by its environment after germination, and the method by which the embryo will free itself from the tissues of the seed.

We have very little exact knowledge on any of these points; the following remarks on each are merely suggestive.

I. The embryo-sac in the ripe seed of many species-Monocotyledons and Dicotyledons alike-is very often long, narrow, and sharply bent on itself. Mrs. Schaffner's drawing of Capsella (76, Fig. 37), Miss Gibbs' drawing of Stellaria (28, Fig. 22), and Professor Schaffner's drawing of Sagittaria (75, Fig. 73), show how the embryo has to accommodate itself in each case to its quarters. The embryo-sac continues to increase in size during the growth of the embryo, which in such forms is confined from the first within a long narrow space. It is further hampered by the presence of a growing endosperm.

2. The food-supply of the pro-embryo is no doubt commonly conveyed through the suspensor. In some forms-as in many of the Leguminous species described by Guignard (31), and those from the Rubiaceae described by Lloyd (54) - the suspensor is very highly specialized as a haustorial organ, is massive and persistent. But, as a rule, it flourishes for a limited period only; long before the seed is ripe the suspensor is withered and clearly no longer functional. Food must then reach the embryo in some other way.

The cotyledons are generally understood to take over the absorptive 
function, and no doubt this is very often true. The few careful observations on the method of food-supply to the growing embryo indicate, however, that there is far more variation in the process than was commonly supposed. Two examples illustrate this.

Professor D. S. Johnson (48) gives good reason to think that in Peperomia the food is supplied to the growing embryo, as to the young seedlings, through the cotyledons. These organs have merely, however, to absorb the food in a soluble form. The work of drawing on the reserves laid up in the perisperm, and preparing them for use, is performed by the scanty endosperm.

Similar results are recorded by Miss Gibbs (28) for the Alsinoideae, with one important variation. Here, as in Peperomia, the endosperm prepares the food which it draws from the perisperm for use by the embryo. But in the Alsinoideae-in Stellaria media, for example-the suspensor is for a long time the absorbent and digestive organ. When the digestive function is assumed by the endosperm, that of absorption falls to the root-tip.

Much more work is needed on this question before we can hope to understand the morphology of the embryo. If the cotyledons commonly absorb food from the endosperm and pass it on, their early appearance in the history of the embryo is sufficiently explained.

3. Finally, the development of the embryo is modified by conditions other than those which act on it directly. The embryo of the ripe seed is not always mature. But whenever the embryo becomes mature it shows signs of adaptation to its past and present environment, to the environment of its immediate future, and to that of a future rather more remote. We have already touched on its adaptations to the conditions surrounding it during the period of growth which has just ended. The next stage will be the exit of the embryo from the seed, and certain features in the mature embryo can be referred to the difficulty of getting free quickly and without damage from the tissues which envelop it in the seed. The peg of gourd seeds is a well-known example (21, p. 22 and Fig. 5), and the action of the wedging roots in the Maize (74, p. I I 6 and Figs. 6-8). Finally, the members of the young seedling are present in the mature embryo, and their structure even in the undeveloped state has a certain reference to the conditions which will be encountered by the seedling. The coleoptile of Grasses, for example, is clearly adapted to pushing up through the soil.

The conditions, then, to which the embryo must conform are sufficiently complicated to account for wide departures in structure from the ancestral type. The question before us is whether those conditions would be likely to produce temporary suppression of the axis in a Monocotyledonous embryo, leading to the formation of an apparently terminal cotyledon. This question cannot as yet be answered directly, for lack of evidence. It is hopeless to attempt to appreciate the effect of conditions so imper- 
fectly understood. But comparison of the normal type with certain exceptional forms is very suggestive.

Solms-Laubach (82) has described the development of the embryo in certain genera belonging to the Commelinaceae and Dioscoreaceae. He has shown that in such forms the cotyledon is lateral from the first, while the stem-bud is terminal. In his figures of Tamus communis the development of the cotyledon is traced from the beginning. It appears as a circular ridge surrounding the region in which the stem-bud will afterwards be formed. Growth in one part of the ridge soon ceases; the opposite region grows rapidly, and the rudimentary cotyledon finally arches over the hollow which contains the stem-bud. In the end the mature embryo is much shorter and broader than that of Alisma, but does not differ very widely from it in general shape.

The embryo-sac is not included in these drawings, but figures in Le Maout and Decaisne's textbook $(52$, p. 795) show the berry and ripe seed whole and in section, as well as the seedling during germination. The ovules are anatropous; the embryo-sac therefore is not bent upon itself as in Alisma and Capsella. The seed is very little longer than broad, and the embryo has in consequence plenty of room to develop laterally during the process of maturation. In Commelinaceae the ovules are peltate (52, p. 868), and of course much broader than long. Here again the embryo has had ample elbow-room within the embryo-sac.

This association of a lateral cotyledon with an unusually wide embryosac is very suggestive. Perhaps the apparently terminal position of the cotyledon in Alisma and the majority of Monocotyledons may have something to do with the long narrow embryo-sacs which are so common. The complete explanation would probably depend on other conditions too. We know far too little of the environment and needs of the growing embryo to attempt such an explanation yet.

Three hypotheses to account for the terminal position of the cotyledon in Alisma and most Monocotyledons have now been discussed. First, that it is a terminal member and therefore no true leaf. Secondly, that it is a terminal member and one of the few leaves surviving to represent the original or ancestral leaf, which according to this view was essentially terminal. Thirdly, that it is a lateral member, forced into a terminal position by causes which we do not fully understand, but believe to be adequate to the task.

Of these three suggestions the last seems the most satisfactory. If adopted, what bearing has it on the original question-the number of cotyledons possessed by the Primitive Angiosperms?

Suppose the single cotyledon of the ancestral Monocotyledon was lateral, was it derived from a single lateral cotyledon in the Primitive 
Angiosperm? If so, the Dicotyledonous pair must have been formed either by the fission of a single lateral member, or by the addition of a second cotyledon to that already in place. The second suggestion is clearly improbable: the first deserves consideration. Such a cotyledon as that of Tamus might conceivably divide, and the segments shift their position until they faced each other. The embryo of Nelumbium as described by Professor Lyon might represent a stage in this process, though-as we have seen-this is not his own interpretation of the facts.

If, on the other hand, the Primitive Angiosperms had two cotyledons, and we treat the single cotyledon of Monocotyledons as a lateral member, it might be derived from the ancestral pair either by suppression of one of them or by the complete union of both.

The embryology of the Pseudomonocotyledons is of the greatest interest in relation to this subject. Scattered here and there within Dicotyledonous genera are a few species which have but one cotyledon. Hegelmaier (37) followed the development of the embryo in three of these species from the fertilized ovum to the ripe seed. They are Ramunculus Ficaria, Corydalis cava, Carum Bulbocastanum.

Unfortunately the embryo of all three species is very little developed in the ripe seed. A long period of maturation is necessary before germination can take place. Hegelmaier failed to secure the maturation stages, and his work was first completed in 1902 by the publication of a posthumous paper by Schmid (78), which carried the history of the embryos on to the epoch of germination. About the same time Sterckx (83) published a complete account of the development of the embryo in Ranunculus Ficaria.

In each of these species the single cotyledon was certainly derived from two. They belong to dicotylar genera ; in other words, the ancestral Corydalis, Carum, and Ranunculus possessed two cotyledons. The single cotyledon in the aberrant species is an adaptation peculiar to themselves. Thus the change from a dicotylar to a monocotylar form has occurred in comparatively recent times-at any rate since the date of the original representative of each genus. Here, if anywhere, we might hope to trace the development of so well-marked a character in the young embryo. We should perhaps expect to find the rudiments of two cotyledons at first, then to trace either the development of the one and the arrest of the other, or their fusion into a single member.

The actual process in all three forms bears a strong resemblance to the development of the embryo in Tamus. The cotyledon appears on the flattened apex of the pro-embryo as a peripheral ridge. At first it is circular, but it soon becomes crescent-shaped by the rapid growth of one side. The stem-apex is often late in appearing. It is always formed in the central depression outlined by the circular ring. Very soon the 
stem-bud is completely dominated by the lateral member, which embraces and at last arches over it. This lateral member is of course the single cotyledon, which becomes apparently terminal in the mature embryo, for it manages to push the stem-apex to one side.

In the interpretation of their results, Hegelmaier and Schmid consider one possibility only-the formation of a single cotyledon from the original pair by suppression of the second. Hegelmaier is inclined to localize the missing cotyledon in that region of the ring where growth first ceases. A projection is formed there from which a sheath-like organ is developed. Schmid, however, considers the projection in this place as equally likely to represent the sheath of the single cotyledon only, and he does not attach much importance to the single abnormal embryo of Carum Bulbocastamum figured and described by Hegelmaier in which this projection is almost as large as the still rudimentary cotyledon (37, P1. VII, Fig. 4I). SolmsLaubach definitely refused to consider a similar formation in the embryo of Tamus communis as anything more than the rudiment of the cotyledonary sheath (82, pp. 85, 86, and Figs. 29-33).

Sterckx (83), on the other hand, dealing with Ramunculus Ficaria only, is much influenced by the bilobed blade of the fully expanded cotyledon (p. 45 and Figs. I76, I77, Pl. XV). The peculiar venation of this blade suggests - as he points out - the fusion of two leaves into a single member. The embryo in his figures also shows a slight but quite definitely bilobed structure (loc. cit., Fig. I 56). He concludes that the single cotyledonary member is in fact a fusion of the two cotyledons which we attribute to the ancestral Ranunculus.

Now, if we agree in this explanation of the single cotyledon of Ranunculus Ficaria, we may equally well interpret the similar structure of the embryo in Corydalis cava and Carum Bulbocastanum in the same way. With the exception of the slightly bilobed cotyledon found in the embryo of Ramunculus Ficaria, the development of all three is precisely alike.

The position of the first leaf, which is opposite the cotyledon, is also an argument for Sterckx's theory. For, if the single cotyledon represents a pair fused along one margin, the first leaf would stand in its proper place relatively to that pair. But if the cotyledon represents one of a pair of which the other has disappeared the abortive cotyledon would stand behind the first leaf, which could not be its original position.

The truth is, however, that there is nothing in the development of the embryo in any one among the three Pseudomonocotyledons just described which will decide between the rival theories. So far as the evidence goes, the single cotyledon in all three might be derived from the ancestral pair either by suppression of one cotyledon or by union of the two into a single member. 
But if embryological evidence fails to answer a comparatively simple question such as the method by which two cotyledons in the ancestral Corydalis, Carum, or Ramunculus became reduced to one in certain living species, how can we expect to settle the number of cotyledons possessed by a form so remote as the Primitive Angiosperm by evidence of the same kind drawn from the structure of its living descendants?

So far the comparison with Pseudomonocotyledons has served merely to confirm previous doubts as to the phylogenetic value of characters belonging to the young embryo. It is pretty clear that such characters are mainly adaptive. Ancestral features seem to be obliterated quickly and very completely at that early period. Two causes probably co-operate to this end: the severity of the competition which follows germination, and the plastic nature of the tissues in the young embryo. A very slight start in the race may mean survival to the seedling, and some minute variation in the structure of the mature embryo may ensure such a start. At the same time slight changes in the form of a mass of meristem are easily effected.

What conclusions can be drawn from the history of the embryo within the embryo-sac? We have discussed three possibilities with regard to the number of cotyledons possessed by the Primitive Angiosperms. First, that they had one cotyledon, which gave rise to the pair found in living Dicotyledons by fission. This possibility is usually thought to involve the existence of a truly terminal cotyledon both in the Primitive Angiosperms and in living Monocotyledons. If this were so, we might well hesitate to accept an explanation which involved such a consequence. The difficulties arising out of this hypothesis have already been discussed. But the development of the embryo in the Pseudomonocotyledons examined by Hegelmaier, Schmid, and Sterckx, and in genera from the Dioscoreaceae and Commelinaceae described by Solms-Laubach, shows how a cotyledon of undoubtedly lateral origin may assume a terminal appearance, pushing the stem-apex to one side. The apparently terminal cotyledon of Alisma and other Monocotyledons may be derived from a single lateral cotyledon through intermediate forms of this kind.

The possibility of a monocotylar race of Primitive Angiosperms need not then be abandoned on the ground that their single cotyledon must needs be terminal. Nor is it impossible to derive a dicotylar embryo from such an ancestor. The single cotyledon might divide to form a pair of members which by lateral shifting would come to oecupy the same relative position as the cotyledons of living Dicotyledons. The view so amended has, however, lost its chief recommendation - that of simplicity. The cotyledons of Capsella can no longer be derived by fission only from the single member found in Alisma. 
Suppose, on the other hand, that the Primitive Angiosperms possessed two cotyledons. They may have been reduced to one in living Monocotyledons by either of two methods. One of the pair may have been suppressed, or both cotyledons may have fused into one. That the change from a dicotylar to a monocotylar embryo can be effected without difficulty is clear from the existence of pseudomonocotyledons-species with a single cotyledon belonging to widely separated Dicotyledonous genera. In each genus the reduction of two cotyledons to one has taken place independently. We have seen that the development of the embryo within the embryo-sac gives no clue to the method by which such reduction takes place-at least in the three species investigated.

Vestiges of a second cotyledon opposite the functional one have been sought in vain by many observers; Hegelmaier believed he had found such a rudiment in the abnormal embryo of Carum Bulbocastanum already mentioned. Little weight need be attached to an isolated instance of this kind. The epiblast of certain Grass embryos has been interpreted as a rudimentary cotyledon (Van Tieghem), but this view is not generally accepted.

Little evidence has so far been brought forward in favour of the third and last possibility, that of the fusion of both cotyledons of the Primitive Angiosperm into a single member. Sterckx attributes the bilobing of the embryo in Ramunculus Ficaria to an origin of this kind, but even if his arguments were conclusive they would not decide the question in the case of true Monocotyledons.

To sum up, comparison with Gymnosperms establishes a presumption in favour of two cotyledons among the Primitive Angiosperms. The development of the embryo within the embryo-sac gives no decided clue to the ancestral form. The shape of the whole structure and the sequence of its development seem far more dependent on the environment than on inheritance of ancestral features.

One class of evidence is as yet untouched-the history of the embryo after germination. The embryo is less cramped when it has escaped from the seed, and the development of vascular tissue gives rigidity to its form. Ancestral features if reproduced after this epoch stand a better chance of being preserved.

\section{Embryology after Germination.}

The anatomy of seedlings cannot be understood apart from their external characters. On germination the outline of the embryo is much altered, but this depends not on the formation of new members but on changes in the proportion of those already present to each other. This is quite clear in the familiar examples of germination-bean, acorn, maize. The exit of the radicle and plumule from the seed is commonly due to the basal elongation of the cotyledon or cotyledons. This elongation is followed, 
perhaps accompanied or even replaced, by that of the hypocotyl. Then follows the lengthening of the primary root, and finally that of the plumule, or of the first leaves. This sequence is the rule in Monocotyledons and Dicotyledons alike, but, of course, exceptions are found in both classes. Seedlings adapt themselves in this as in other respects to the demands of their environment.

In every seedling there is a period-longer in some species, shorter in others-during which it consists of cotyledons, hypocotyl, and primary root. The plumular bud is of course present, but neither its axis nor the petioles of its leaves have begun to elongate. It is insignificant compared to the cotyledons. During this period the vascular tissue within the seedling becomes well-defined for the first time. Lignification of the xylem sets in -a change of great importance to the microscopist, since it permits him to pick out the first xylem elements with certainty from other constituents of the bundle. In many slow-growing seedlings the vascular skeleton of the cotyledons, hypocotyl, and primary root, is fairly complete before the plumular traces are well differentiated. In such forms this vascular skeleton is often found to be characteristic of the genus, or even of a larger group. In other words, the skeleton is formed on the same type throughout the genus or the order. Simple as this skeleton necessarily is, more variation in detail is possible within it than might be expected. The number of traces furnished by each cotyledon, their behaviour in the hypocotyl during the transition to a root-structure, the symmetry of the primary root, are all variable characters. Very well-marked types of vascular symmetry can be distinguished, and some of these are clearly derived from others. Thus extended observations show some types to be more primitive than others.

The seedlings of Monocotyledons and Dicotyledons have been examined of late years with a phylogenetic aim. General conclusions have been drawn from comparison of the several types of vascular symmetry found within each class. If such investigations should show that there is a primitive type in each class, we may fairly suppose it to represent the seedling skeleton of the ancestral Dicotyledon or the ancestral Monocotyledon. But of course the primitive or ancestral Dicotyledon and the primitive Monocotyledon are nearer to their common ancestor than living Dicotyledons and living Monocotyledons are. Therefore the primitive forms in either class should resemble each other more closely than living Dicotyledons resemble living Monocotyledons.

Some fairly extensive observations on the vascular symmetry of seedling Monocotyledons have shown that one particular type of monocotylar symmetry may be considered relatively primitive (Sargant, 72). A certain dicotylar type has also been picked out as relatively primitive by other observers, partly by comparison of Dicotyledonous seedlings with each other, but chiefly as the result of comparison with Gymnosperms 
(Tansley and Thomas, 87 ; see also Thomas, 88). If these observations are well-founded, the two primitive types ought to resemble each other. If they do, the results in either case are strongly confirmed. If they do not, there must be some flaw in the reasoning on one side or on both.

This test has in fact proved satisfactory. The two types of vascular structure resemble each other very closely. The points which they have in common represent, no doubt, the seedling structure of the Primitive Angiosperms. But the important feature for our present purpose is this. The seedling structure of the primitive Monocotyledon resembles that of the primitive Dicotyledon in its dual symmetry. In other words, judging by its vascular skeleton, the seedling of the Primitive Angiosperm was dicotylar.

The importance of this result renders an examination of the evidence on which it is based imperative. The account which follows is necessarily a mere sketch. For convenience it begins with the Dicotyledons. The external features of their seedlings are more familiar to botanists, a greater mass of evidence concerning their internal structure is available, and their vascular symmetry is less variable and more easily described.

The most important series of researches hitherto made on the anatomy of Dicotyledonous seedlings from a phylogenetic standpoint is that carried out by Mr. A. G. Tansley and Miss Thomas. It is as yet published only in abstract. But in the light of their results previous work such as that of Gérard (27), Dangeard (20), and others acquires a new value. The seedling anatomy of Dicotyledons had been examined much more fully than that of Monocotyledons before the microtome came into common use. The suppression of the internodes, which is characteristic of Monocotyledonous seedlings, was indeed a formidable obstacle to research when the only possible method of examination was by successive hand-sections. But hand-sections could be used for the fairly long internodes of Dicotyledons.

Thus Gérard, in his elaborate memoir of 188 I (27), described fifty-seven species of Dicotyledons, giving every detail of the transition from root to stem in the young seedling, but he attacked only nine species of Monocotyledons. And as these were necessarily chosen because they possessed fairly long hypocotyls and plumular internodes, they did not properly represent their class.

Dangeard gave a more general sketch of the anatomy of Dicotyledonous seedlings in I 889 (20), and we have, in addition, accounts of isolated families or genera by Van Tieghem, Quéva, Sterckx, Chauveaud and others. These researches have for the most part been directed to an anatomical end--the description of the transition from root to stem-structure in the hypocotyl.

The evidence then to which I shall refer is, in the first place, that collected by Mr. Tansley and Miss Thomas. In the account which follows I have drawn largely on both the published abstracts dealing with their work 
$(87,88)$. The generosity of the authors has allowed me to verify details by examination of their original preparations. Their researches deal, as already stated, with Gymnosperms as well as Dicotyledons.

Next in importance comes recent work inspired by the same phylogenetic aim, but dealing with comparatively small groups (T. G. Hill, 40, 41 ; A. W. Hill, 39 ; Matte, 60 ; Hill and de Fraine, 42). Finally we have the anatomical literature just quoted as corroborative evidence.

After my own experience of Monocotyledons with their endless variety in detail, the uniformity of Dicotyledons is very striking. The hypocotyl and primary root form part of the main axis of the plant. In annuals, biennials, some perennials, and in most trees, they last its life. They commonly survive for several seasons even when not permanent. Accordingly these organs become adapted to their functions in a way rarely found among Monocotyledons. The survival of variations in their structure depends on conditions affecting the plant during its whole life, not on those alone which immediately succeed its germination. We have in consequence a tendency to uniformity in the primary structure of the hypocotyl and primary root, because it reflects the permanent conditions of life, and these are uniform, too, in the long run. Moreover, in Dicotyledons the primary structure of root and stem alike is subordinate to the secondary structure, and this is uniform throughout the class.

Accordingly the Dicotyledons as yet examined display but two distinct types of seedling structure. Both are widely distributed within the group. The extreme forms of each type are connected by intermediate links. The types may be distinguished as tetrarch and diarch (Thomas, 88, pp. 79-8I ; Dangeard, 20).

In both types the blade of each cotyledon possesses a midrib, and, as a rule, two main lateral bundles. All three bundles enter the petiole and commonly fuse there, but occasionally they are found as distinct traces within the hypocotyl, and do not unite even during their insertion on the stele.

In the diarch type the lateral traces always unite with the midrib before its insertion on the stele, though complete fusion is sometimes postponed very late. Mechanical reasons may sometimes determine the level of the junction. Thus in Nigella damascena the petioles of the cotyledons are quite $10 \mathrm{~mm}$. long (Fig. 7). The midrib runs down the middle of each petiole, and a lateral bundle stiffens either edge (Fig. 8). In the much shorter petioles of Delphinium requienii (Fig. I) the laterals are inserted on the midrib at the base of the blade (Fig. 3). The fusion bundle can be followed down the petiole, and in transverse section it shows the curious double structure (Fig. 2). The phloem groups are distinct : the metaxylem groups are partially divided from each other by a single group of protoxylem, common to both divisions of the bundle. In Nigella the midrib trace shows a similar double structure at the base of the petiole 
just before the insertion of the lateral traces on it. When this insertion takes place, which is not until the three traces are close to the stele of the hypocotyl, the symmetry of the midrib-trace is not affected.
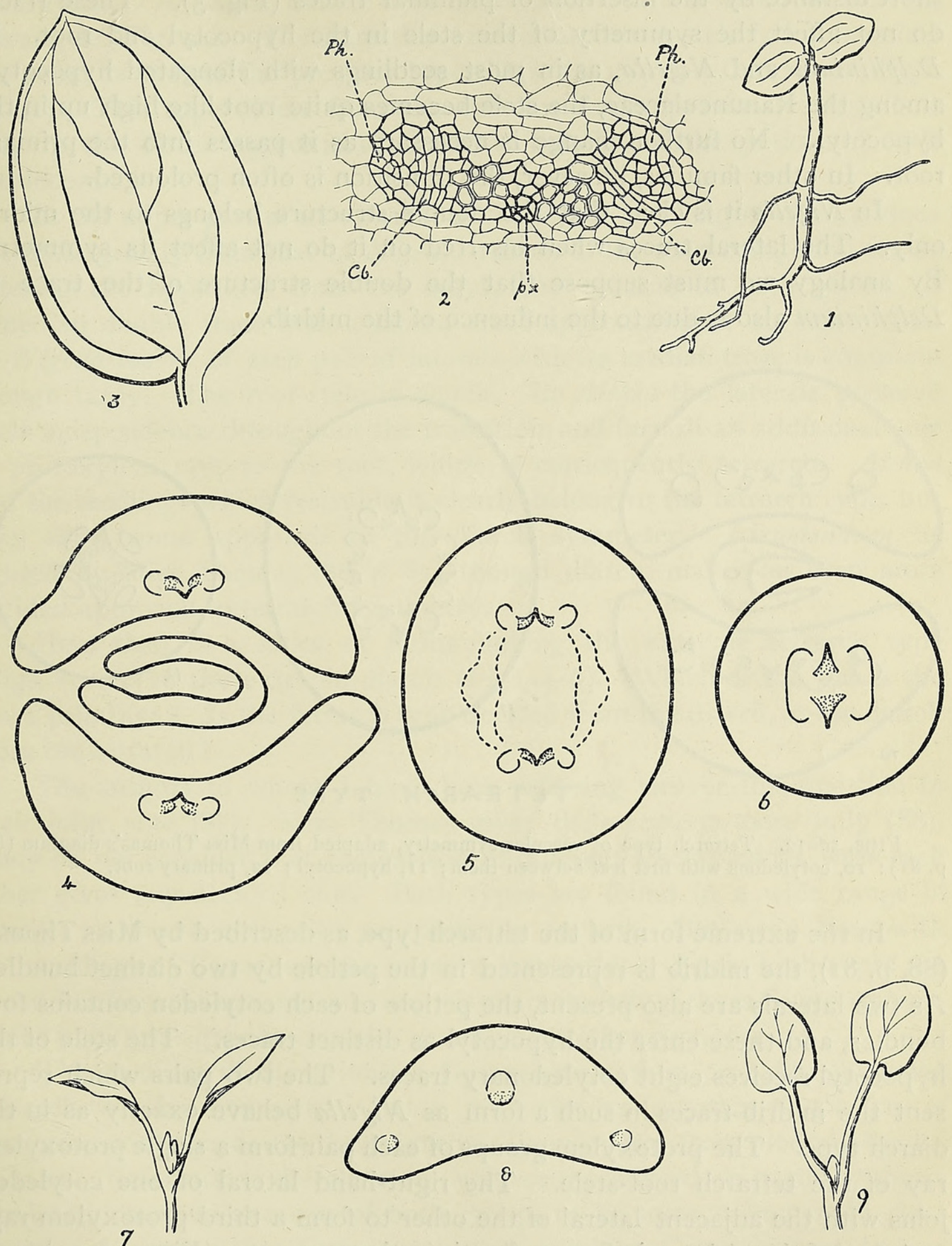

FIGs. I-6. Delphinium requienii: I, seedling, showing nearly sessile cotyledons; 2 , double bundle from petiole of cotyledon; 3 , cotyledon (enlarged), showing venation ; 4-6, diagrams of transition from stem to root. Here, as in later diagrams, protoxylem is black, metaxylem dotted, and phloem merely outlined.

Figs. 7, 8. Nigella damascena: 7, upper part of seedling; 8, transverse section of petiole of cotyledon.

Fig. 9. Althea rosea : upper part of seedling. 
The protoxylem of the double trace is often completely external by the time it enters the stele of the hypocotyl, and the transition to a diarch root-stele is then very simple (Figs. 4-6), though commonly delayed for a short distance by the insertion of plumular traces (Fig. 5). These traces do not affect the symmetry of the stele in the hypocotyl and root. In Delphinium and Nigella, as in most seedlings with elongated hypocotyls among the Ranunculaceae, the stele becomes quite root-like high up in the hypocotyl. No further change is necessary as it passes into the primary root. In other families, however, the transition is often prolonged.

In Nigella it is clear that the double structure belongs to the midrib only. The lateral traces when inserted on it do not affect its symmetry. By analogy we must suppose that the double structure of the trace in Delphinium also is due to the influence of the midrib.
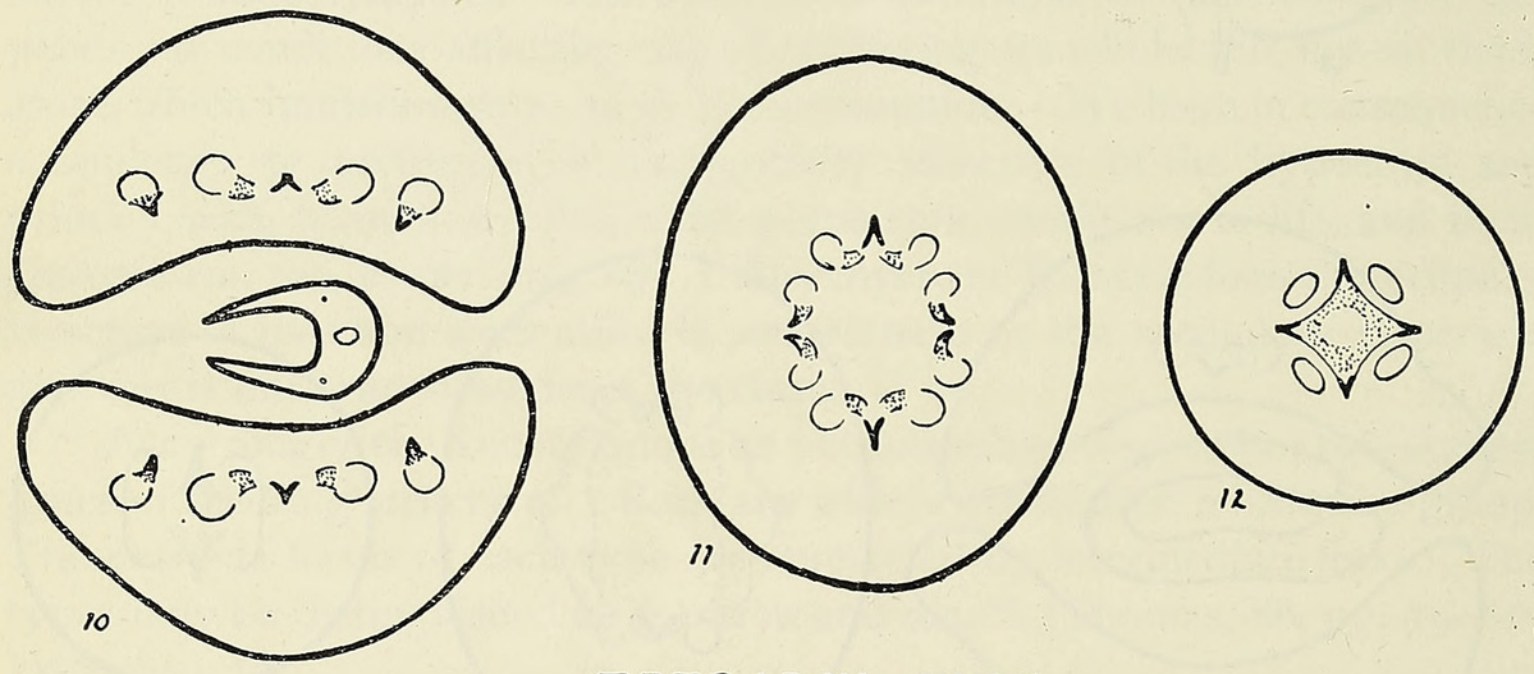

TETRARCH TYPE

FIgS. IO-I2. 'Tetrarch type of vascular symmetry, adapted from Miss Thomas's diagram (88, p. 8I): Io, cotyledons with first leaf between them; I I, hypocotyl ; I2, primary root.

In the extreme form of the tetrarch type, as described by Miss Thomas $(88$, p. $8 \mathrm{I})$, the midrib is represented in the petiole by two distinct bundles. As two laterals are also present, the petiole of each cotyledon contains four bundles, and these enter the hypocotyl as distinct traces. The stele of the hypocotyl receives eight cotyledonary traces. The two pairs which represent the midrib-traces in such a form as Nigella behave exactly as in the diarch type. The protoxylem groups of each pair form a single protoxylem ray of the tetrarch root-stele. The right-hand lateral of one cotyledon joins with the adjacent lateral of the other to form a third protoxylem ray, and the left-hand laterals form a fourth in the same way (Figs. IO-I2).

This extreme case is less frequent than the symmetry described by Gerard in Althea rosea, a form also included within the tetrarch type of Mr. Tansley and Miss Thomas (87, also 88, p. 80). The bundles from the blade approach each other very closely in the long petiole of the cotyledon 
(Fig. 9). The laterals are in contact with the double trace of the midrib, though they have not fused with it (Fig. 13, p. I70). The trace which enters the stele of the hypocotyl consists of a median double bundle with external protoxylem. A lateral bundle is in close contact with it on either side (cf. Gérard, 27, Fig. 24). The transition to a tetrarch root-stele is in essentials the same as that of the previous type (Figs. I4, I5; and Gérard, 27, Figs. $\left.23^{-2} \mathrm{I}\right)$. This type differs from the extreme forms previously described only in the closer approximation of the bundles in the petiole of each cotyledon.

In the upper part of its vascular skeleton, the seedling of Althea does not differ greatly from that of Nigella. Each of the twin compound traces entering the hypocotyl from the cotyledons consists in both genera of a median double trace with a lateral trace approaching it on either side. In Nigella fusion of each pair of laterals with its median trace is complete though tardy. The root-stele is diarch. In Althea the laterals preserve their independence throughout the transition, and furnish an additional pair of protoxylem rays to the root, which is consequently tetrarch. Althea and the seedlings which resemble it clearly belong to the tetrarch type, but they show some approach to the diarch symmetry. Liriodendron, as figured by Miss Thomas (88, p. 8I), though diarch, makes an even more decided approach to tetrarch symmetry.

Here then is a series of forms linking the extreme tetrarch type (Figs. 10-12) to the extreme diarch (Figs. 4-6). Which of the two is the more primitive? Is the tetrarch type derived from the diarch, or the diarch from the tetrarch?

The authors to whom I have been referring answer this question in their joint note (87). Miss Thomas gives their reasons more fully (88). They do not consider that comparison of different Dicotyledons with each other gives any decided clue. Both types are found in a wide range of families; some in either list are probably ancient. But comparison with the seedlings of Gymnosperms is more instructive. Again both types are found, but here the tetrarch symmetry is characteristic of those Gymnosperms which botanists agree to consider primitive on other grounds.

The seedling of the primitive Gymnosperm, then, probably possessed tetrarch vascular symmetry. But it must not be forgotten that a gap of enormous width separates the primitive Gymnosperm from modern Angiosperms. Reference to the skeleton pedigree reproduced on page $\mathbf{I} 37$ shows the latest common ancestor of both groups to be some unknown Pteridosperm. Assuming that Cycads and other primitive Gymnosperms derived the tetrarch symmetry of their seedlings from this Pteridospermic ancestor, we make a second and a greater assumption in supposing that the tetrarch symmetry of modern Dicotyledons has come down unchanged through countless generations of Hemiangiosperms to the Primitive Angiosperms, 
and thence through a shorter but still very long period to some living Dicotyledons.

Considering the enormously long epochs with which we are dealing, it might be argued that the two cotyledons of modern Dicotyledons, and the tetrarch skeleton found in many of their seedlings, are not derived from the same source as those characters in living Cycads. The ancestral Pteridosperm may not have possessed them, or if it did perhaps they were lost during the gradual evolution of Primitive Angiosperms through a series of Hemiangiospermous forms. In either case these characters would not have been handed down directly from Pteridosperms to modern Dicotyledons on the one hand and Cycads on the other.

Even on the evidence already given, it must be admitted, however, that the theory of a common origin for these characters supplies the simplest explanation of the facts. The burden of proof lies with those who dispute it. But this is not all. There is evidence from other sources to show that the seedlings of Primitive Angiosperms possessed two cotyledons and tetrarch symmetry.

The Bennettiteae probably diverged from the main Angiospermous line of descent at a later period than the Cycads. But the embryo of the Bennettitean seed is always dicotylar. This increases the presumption derived from the two cotyledons of Cycads, that the descendants of the ancestral Pteridosperm were dicotylar too, and suggests that they retained that character at least as late as the period at which the Bennettitean race was given off. This brings us nearer to the Primitive Angiosperms on one side. On the other lie the Primitive Dicotyledons and the Primitive Monocotyledons. So far as internal evidence goes, the seedling of the Primitive Dicotyledon may have shown either diarch or tetrarch symmetry. What is known about the seedling of the Primitive Monocotyledon?

Among Monocotyledons as among Dicotyledons there is a period in the history of the seedling during which it consists of cotyledon, hypocotyl, and primary root. The plumular bud is still quite embryonic, and is as a rule completely enclosed by the base of the cotyledon, or by a sheath-like appendage attached to it. But in Monocotyledons the primary root as well as the single cotyledon is commonly a short-lived structure. The hypocotyl is almost always much reduced in length, even when it is not transformed into a tuber. The young seedling then to all appearance consists only of cotyledon and primary root-two short-lived members separated by a brief region representing the hypocotylar axis. In many genera this region hardly exists at all ; the cotyledon seems to pass directly into the primary root. The early internodes of the stem are frequently much suppressed too, and the early leaves then appear directly connected with the first cauline roots. Such leaves do not receive their water-supply through the main axis 
as in Dicotyledons, but directly from the roots to which they are respectively attached.

The primary root then naturally withers away at the same time with the cotyledon. They rarely survive the first season of growth, and their structure-external and internal-is therefore affected by those conditions only which immediately succeed germination. With the later life of the plant they have nothing to do. This peculiarity accounts for the much greater variety of internal structure found in the young seedling of Monocotyledons as compared with that of Dicotyledons.

In consequence of this variety the results of such an examination cannot be so clearly defined. But, on the other hand, the vascular characters of the seedling are of more taxonomic value among Monocotyledons than among Dicotyledons. A genus or a group of genera is very often separated from its fellows by the characteristic vascular skeleton of its seedling.

Two distinct types of vascular skeleton are often connected with each other by a series of intermediate forms. When such forms constitute a single series-such, for instance, as that connecting the diarch with the tetrarch type among Dicotyledons - there is usually no way of determining which of the two extreme cases is the more primitive. But when, as sometimes happens, several series start from a single type, when, that is, this single type is connected with two or more very distinct forms by two or more distinct series of links ; then there is very good ground for supposing the type common to all the series to be primitive. For it is generally acknowledged that the descendants of a primitive stock may be modified in various ways, until several races are evolved which differ very considerably from each other both externally and internally. But it is far more difficult to imagine causes sufficiently potent to lead even two distinct forms to complete identity in internal structure. And this difficulty is enormously increased when we start with more than two.

By comparison of seedling symmetry in the genera belonging to a single family, it is thus possible to pick out a type of seedling structure as relatively primitive within that family. This has been attempted in the Liliaceae (Sargant, 72). The seedling of Anemarrhena, a monotypic genus belonging to the Asphodeleae, possesses a very definite and characteristic vascular skeleton (Sargant, 70). The vascular skeletons of seedlings belonging to other genera of the Asphodeleae can be derived from the Anemarrhena type; many of them are, indeed, merely variants on it. The vascular symmetry of seedlings belonging to another tribe, the Allieae, is linked to the Anemarrhena type through Arthropodium. Thus comparative evidence suggests that Anemarrhena is primitive as compared with other genera found in these two tribes. But this is not all. The Anemarrhena structure reappears in Galtonia and Albuca which belong to the Scilleae. The very numerous types of vascular symmetry found within this tribe, and also the 
type characteristic of the Tulipeae, can be derived from the seedling skeleton of Albuca or Galtonia, which must therefore be primitive in these tribes too.

Thus the various types of seedling symmetry which have been found within the four tribes, Asphodeleae, Alliceae, Scilleae, and Tulipeae, appear to be founded on the Anemarrhena skeleton. But these four tribes occupy a central position within the family. Together with the Hemerocalleae, the Aloineae, the Yuccoideae, and the little-known Johnsonieae (or Aphyllantheae), they constitute the Liliaceae in the narrowest sense. The eight tribes just mentioned are united by $\mathrm{Mr}$. J. G. Baker in the sub-order Liliaceae verae (6, pp. 354-6, and 7, pp. 209, 210). The seedlings of the Aloineae and Yuccoideae which I have examined have been so far modified by the conditions under which they germinate that most primitive features are lost $(72$, p. 34). Hemerocallis fulva shows a general resemblance to the stouter Scilleae, such as Eucomis. Nothing is known of seedling anatomy in the Johnsonieae. So far, then, it would seem that the Anemarrhena seedling presents the most ancient type of vascular symmetry found among the Liliaceae proper.

The other tribes included among the Liliaceae by Baillon (5) or Bentham and Hooker have all been treated at some time or other as belonging to distinct families. Thus in the English translation of Le Maout and Decaisne's textbook (52, p. 846) the family Liliaceae corresponds pretty closely to Mr. Baker's sub-order Liliaceae verae, and the Junceae, Aspidistreae, Melanthaceae, Smilaceae and Asparageae are treated as distinct families. A note is added to the Liliaceae: 'We have indicated the extremely close affinities between Liliaceae, Asparageae, and Smilaceae; families which together form a group to which most other Monocotyledonous families may be linked, directly or by intermediates. Thus Junceae, which are near certain Melanthaceae and Liliaceae, connect these with other families with a free ovary; and, on the other hand, those Amaryllideae and Dioscoreae which belong, the one to the Liliaceae, the other to the Smilaceae with an inferior ovary, connect them with the epigynous Monocotyledons.'

The seedling structure of Monocotyledons, so far as it has been examined, is not inconsistent with the view expressed in this quotation. The outlying tribes of Liliaceae in the larger sense possess seedlings whose vascular symmetry can be referred to one type or another belonging to one of the four central tribes. The Amaryllidaceae, Iridaceae, and Aroideae, seem similarly attached by seedling characters to the Liliaceae proper. The seedlings of Palmae, Scitamineae, and Gramineae, indeed, are very distinct, but they are all much modified forms, and there is nothing in their seedling structure to suggest a primitive symmetry other than that of Anemarrhena. Indeed, many points in the vascular skeleton of Elettaria 
and other genera of the Scitamineae recall the tetrarch symmetry of Anemarrhena (72, pp. $3^{8-40}$, and pp. 50-52).

The Anemarrhena type, then, may very well be primitive among Monocotyledons in general as well as among the Liliaceae proper. But if so, it will probably reproduce the main features of the seedling in the primitive Monocotyledons. The exact structure of this type is therefore of importance in the present inquiry.

The cotyledon in Anemarrhena, Albuca, and Galtonia is erect and green. The apex is enclosed within the seed, and commonly carries the shell of the seed above ground with it (Sargant, 70 and 72). The primary root is long and stout; externally it appears as the direct prolongation of the cotyledon, from which it is divided only by the slight swelling which marks the position of the future bulb or tuber. Two massive bundles traverse the cotyledon from apex to base. Above the plumular bud they occupy the foci of the elliptical transverse section (Fig. 16). They are symmetrically placed in the sheath and below the plumular bud-the traces of which remain embryonic long after germination--the two cotyledonary traces meet in the centre of the circular section to form the stele of the hypocotyl (Fig. I7). As they approach, each trace opens out into a double bundle, resembling in essentials that of Delphinium (Fig. 2). Before the double traces meet, the xylem of each branches in three directions (Fig. I7), and for a very short distance there are six protoxylem rays and four phloem groups in the stele. Below this the stele becomes root-like and tetrarch by union of two pairs of adjacent lateral protoxylems (Fig. I8).

The resemblance to the vascular skeleton of Althea needs no comment. It is startling when the diagrams are compared (Figs. I3-I5 and I6-I8). But Althea is a mere variant, very slightly reduced, on the tetrarch structure which is certainly primitive among Gymnosperms (Figs. IO-I2), and probably primitive among Dicotyledons. We have seen that the seedlings of primitive Dicotyledons must have been either diarch or tetrarch in their vascular symmetry. Comparison with the seedlings of Gymnosperms inclines the scale in favour of the tetrarch type. This comparison, however, cannot be held to settle the question, because living Cycads are very remote from living Dicotyledons (ante, p. 165). The presumption is undoubtedly in favour of the tetrarch symmetry of seedlings among the primitive Dicotyledons.

This presumption is increased almost to certainty by comparison with Monocotyledons. We have seen that the tetrarch type of symmetry reappears among them. It reappears in seedlings believed on independent grounds to represent a type of vascular symmetry primitive among Monocotyledons. In other words, the evidence suggests that the seedling of the primitive Monocotyledon was tetrarch. 

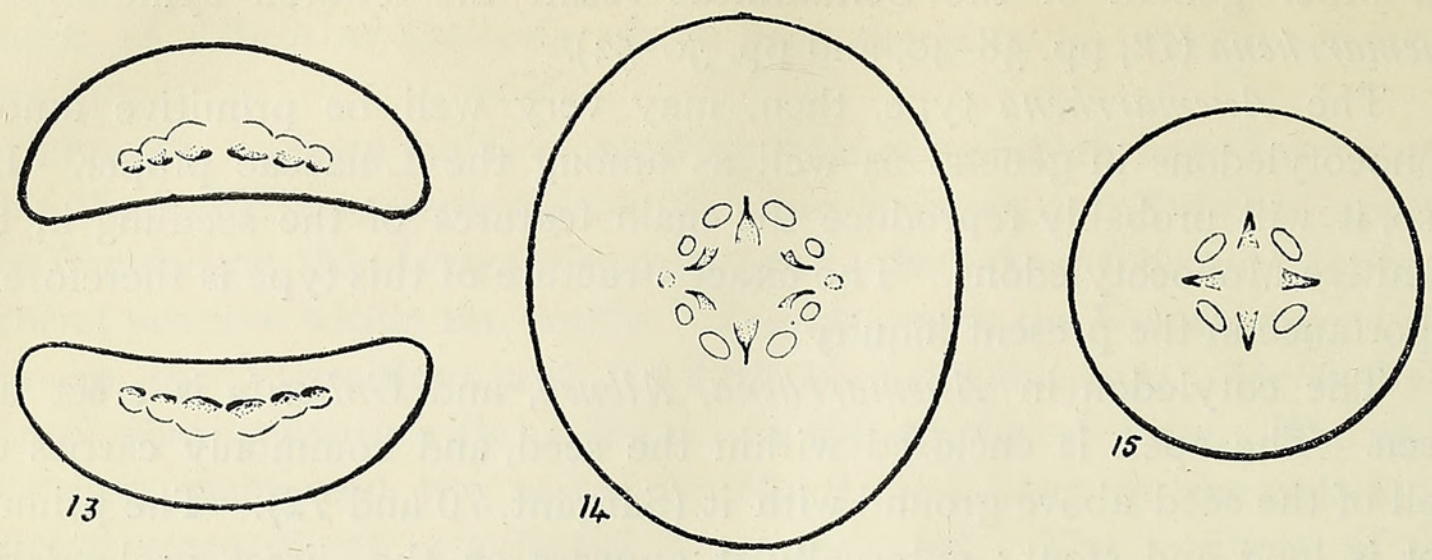

\section{ALTHEA ROSEA}
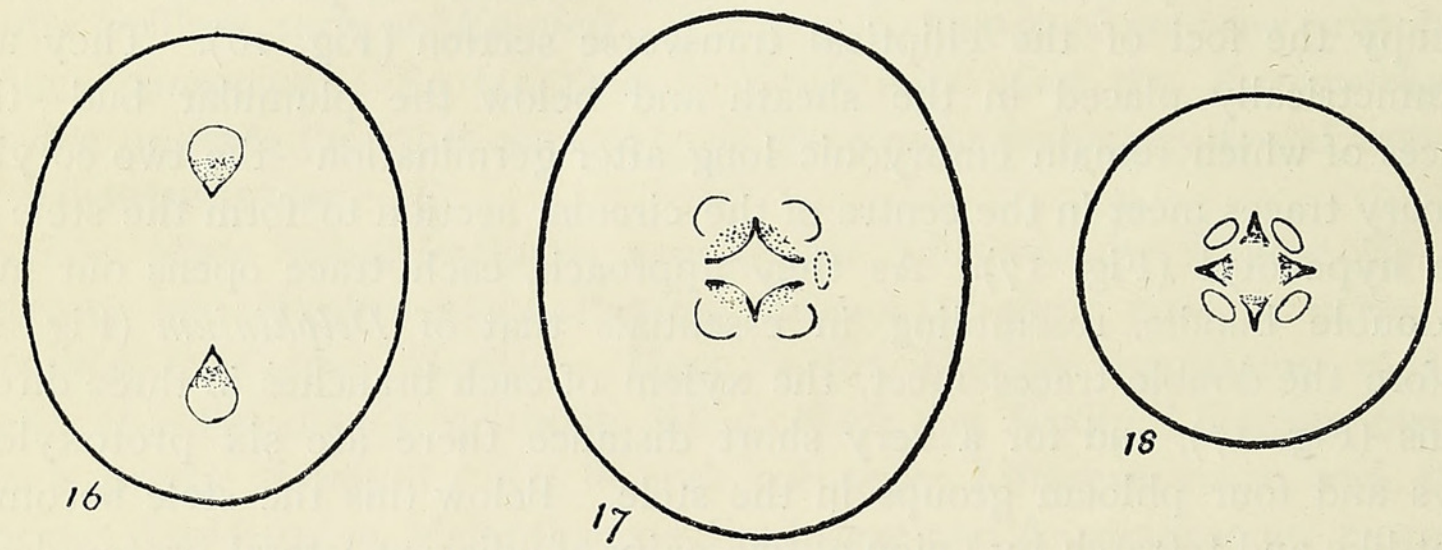

\section{ANEMARRHENA ASPHODELOIDES}
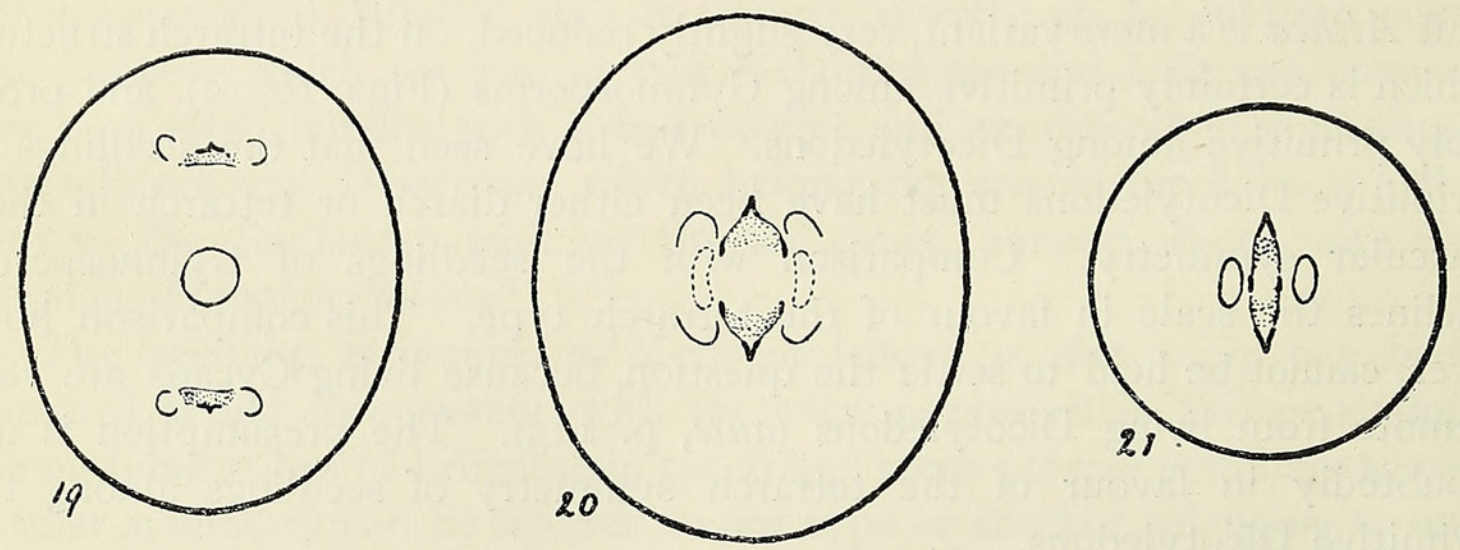

\section{PODOPHYLLUM PELTATUM}

FIGS. I3-2I. Three series of diagrams showing transition from stem to root structure. In each series the first section passes through the petiole of each cotyledon above the stem-bud, the second through the hypocotyl, and the third through the primary root, just below the transitional region.

FIgs. I3-I5, Althea rosea; 16-18, Anemarrhena asphodeloides; 19-2 I, Podophyllum peltatum. 
This similarity in structure between the seedling of the primitive Monocotyledon and that of the primitive Dicotyledon is precisely what was foreseen on theoretical grounds (ante, p. I60). It confirms the results derived from study of the evidence relating to both classes. It is completely and simply explained by supposing the seedling of the Primitive Angiosperm to have possessed tetrarch vascular symmetry which it handed down with more or less modification to its immediate descendants, monocotylar or dicotylar.

If this be accepted as a working hypothesis, does it follow that the embryo and seedling of the Primitive Angiosperms had two cotyledons? The seedling of Anemarrhena has but one, yet its tetrarch symmetry is very clear. Might not a monocotylar Primitive Angiosperm give rise to tetrarch dicotylar forms, as well as a dicotylar Primitive Angiosperm to tetrarch monocotylar forms?

If the alternatives are followed out to their consequences, the second hypothesis-that of the dicotylar Primitive Angiosperm-is certainly far more probable. Any stele which receives traces from two similar and opposite cotyledons, each symmetrical about the same median plane, must itself be symmetrical about two vertical planes : that is, about the median plane common to both cotyledons, and about the intercotyledonary plane perpendicular to it. The reduced or diarch type of skeleton described in the seedlings of Delphinium and Nigella is as completely symmetrical about both planes as the tetrarch skeleton of Althea. Reduction within the seedlings of Dicotyledons does not tend to produce a skeleton symmetrical about one plane only. On the other hand, a stele receiving traces from a single lateral member is naturally symmetrical about the median plane of that member, but not necessarily or even probably symmetrical about the vertical plane at right angles to it.

Accordingly, among Monocotyledons, the tetrarch skeleton as it is found in Anemarrhena, Albuca, and Galtonia, is the only type symmetrical about two planes. Even in these cases symmetry about the plane bisecting the cotyledonary traces is not quite complete, for these traces are slightly displaced in one region of the axis by the insertion of the plumule (Sargant, 72, Diagram VI (A), pp. 26 and 70, Fig. 3).

That the tetrarch skeleton, symmetrical about two vertical planes, should be found in Monocotyledonous seedlings of an ancient type is exactly what would occur if the primitive Monocotyledon were derived from a dicotylar ancestor by the fusion of both cotyledons into a single member. The dual symmetry of the internal structure would naturally survive the external bisymmetry. On this hypothesis we may suppose that two cotyledons were characteristic of the main line of Angiospermic descent from the original Pteridosperm down to the evolution of the primitive 
Monocotyledon. The two cotyledons of Cycads and of the Bennettiteae would be derived from ancestors in that line of descent.

But the case is very different if we are to postulate a monocotylar Primitive Angiosperm. We must then either give up the connexion with the Cycads and the Bennettiteae altogether, or suppose that the monocotylar form of seedling was evolved in an ancestor of the Primitive Angiosperms more recent than that which they have in common with the Bennettiteae. From the monocotylar seedling of Primitive Angiosperms derived in this way, a dicotylar race must be again evolved from which modern Dicotyledons are descended. Further, some descendants of this comparatively modern dicotylar race must reproduce the tetrarch seedling structure of the Cycads. The least improbable form which this hypothesis could take would be to suppose the seedling of Primitive Angiosperms to resemble that of Anemarrhena. That is, it would be completely monocotylar externally, but its vascular skeleton would remain tetrarch. But if we are to credit the Primitive Angiosperms with this partial assumption of monocotylar symmetry, we burden ourselves with the necessity of explaining why the main body of its descendants should have reverted to the dicotylar form. All these difficulties are escaped if we suppose the Primitive Angiosperms to have possessed two cotyledons, united in living Monocotyledons to form a single member.

The antiquity of the dicotylar type is suggested by all the evidence which we possess at present. But so far the suggestion that the pair of cotyledons characteristic of Primitive Angiosperms united to form a single member in one branch of its descendants depends only on the evidence for the comparative antiquity of the Anemarrhena type of vascular symmetry. This is, indeed, the chief argument in its favour. But corroborative evidence is found in the vascular structure of some Ranal seedlings with cotyledons united almost to the top. Eranthis hiemalis has been described elsewhere (Sargant, 71 and 72). Its seedling skeleton is very similar to that of Anemarrhena. The stele of the primary root is indeed diarch in Eranthis. But at the level where the root meets the tuberous hypocotyl there are marked indications of a tetrarch structure. Podophyllum peltatum has a similar seedling (Holm, 45). Its anatomy has not hitherto been described in detail. The main features of its vascular skeleton are given in Figs. I9-21 (p. I70).

Just above the plumular bud the united petioles of the cotyledons are almost solid. The outline of the section is elliptical, the bore of the tube very narrow, and the two traces occupy the foci of the ellipse. Each trace is clearly double: the protoxylem is already becoming external (Fig. I9). The hypocotyl is not swollen into a tuber, though its tissues are packed with starch. As the cotyledonary traces approach the centre, they are 
joined by traces from the rudimentary plumule. The protoxylem of each cotyledonary trace branches in three directions: the four phloem groups remain distinct for some time. The resemblance of the stele at this level in transverse section (Fig. 20) to that of Anemarrhena (Fig. I7), and Althea (Fig. I4), is very clear. But in Podophyllum as in Evanthis the four phloem groups do not remain distinct. They unite in pairs lower down, opposite the intercotyledonary poles of protoxylem (Fig. 2 I), and the latter finally disappear, leaving a completely diarch root-stele.

In Podophyllum and Eranthis the two cotyledons are united for at least four-fifths of their whole length, and in both the vascular skeleton shows signs of reduction from the tetrarch type. This reduction seems to have begun as in Althea, but to have proceeded further. The fusion of the lateral traces with the midrib is more complete in the petioles. The formation of a tetrarch root-stele is merely indicated: the final form is diarch.

Now the Anemarrhena symmetry can also be considered as a reduction from the Althea type. The reduction in the root-stele is less complete than that of Podophyllum. On the other hand, the bundles of the petioleso clearly double in Podophyllum (Fig. I9)-are single in Anemarrhena (Fig. I6): their double structure is indicated only just before the transition begins. In spite of these differences, the general resemblance between the vascular skeleton of the Anemarrhena seedling and that of Podophyllum or Evanthis cannot be denied. It appears, then, that the partial union of cotyledons in a tetrarch seedling has actually operated to reduce the vascular skeleton to a form very near the Anemarrhena type. Whether the facts imply any real relationship between the Ranales and the Liliaceae or not, they do at least show that union of the cotyledons in a tetrarch dicotylar seedling might bring about the formation of a monocotylar type with a reduced vascular skeleton resembling that of Anemarrhena.

\section{Phylogenetic Schemes.}

The two characters which separate Monocotyledons from Dicotyledons most completely have now been discussed. Primitive Angiosperms appear to have resembled their Dicotyledonous descendants in both. There can be little doubt that they possessed a cambium. The evidence is perhaps less conclusive with regard to the number of cotyledons, but still there seems good reason to think that Primitive Angiosperms had two. The embryological evidence on which this conclusion is chiefly based requires also that the single cotyledon of Monocotyledons should be regarded as a fusion of the ancestral pair.

Monocotyledons, however, differ from Dicotyledons in a number of other characters. From the systematic point of view they are of minor importance, because they are far less constant than those already discussed. Leaves with parallel venation are, for example, the rule among Mono- 
cotyledons and rather rare among Dicotyledons, but quite a large number of Monocotyledons have net-veined leaves. Again, the three-fold symmetry of the flower is quite characteristic of Monocotyledons, but some Dicotyledons display it, while many Monocotyledons have whorls of four or even five parts. So with other characters, such as the short-lived primary root of Monocotyledons and their albuminous seeds. Though no one of these minor characters can be used as a test in the same way as the stem-anatomy or the number of cotyledons, yet collectively they do separate Monocotyledons from Dicotyledons very completely.

This consideration suggests another way of attacking the whole problem. Whichever view we take, for example, concerning the number of cotyledons possessed by the Primitive Angiosperms, whether with Professor Lyon we suppose it monocotylar, or dicotylar with Professor Henslow, one branch of its descendants must be considered as inheriting the original character, and the other as modified in that respect. If the seedling of Primitive Angiosperms was monocotylar, then the two cotyledons of Dicotyledons were developed from the single ancestral member. If the Primitive Angiosperms had two cotyledons, then the single member of Monocotyledons is the innovation.

In either case some cause must have existed for the change. The variations in that direction would not have survived had not circumstances prevailed under which the new structure was in some respects preferable to the old. And it is probable that some of the other characters now associated with the possession of one cotyledon, or of two, were differentiated in response to the same circumstances.

We may, then, inquire whether any causes have been suggested to account for the formation of two cotyledons from one or one from two. And if more than one view has been advanced, which of them would best explain the correlation of stem-anatomy and minor characters with the derived form?

To begin with the theory of a primitive single cotyledon giving rise to a pair by fission, how does it stand this test? Professor H. L. Lyon is the most recent exponent of this view. His papers $(57,58)$ are remarkable for the precision of their statements, and for the unflinching way in which he faces the theoretical consequences of his views. But the only hint given as to the cause of the fission by which one cotyledon becomes two is the suggestion that a bifid cotyledon might be of use to the embryo while it is getting clear of the seed. No attempt is made to correlate the stem anatomy of Dicotyledons, or any of their minor characters, with the dicotylar form of their seedlings.

This omission is not peculiar to Professor Lyon. The monocotylar theory has been accepted by most botanists for more than a generation, 
and it has proved barren. No consistent explanation of the derivation of Dicotyledons from a monocotylar race has yet been offered which would account for the difference in stem anatomy and in some minor features which exists between the two classes. This is in itself a strong argument against the truth of the monocotylar view, and serves to confirm the evidence in favour of crediting the Primitive Angiosperms with two cotyledons.

Assuming that the seedling of Primitive Angiosperms was dicotylar, we have to account for the origin of Monocotyledons. Most of the few botanists who upheld this view in the last century supposed the single cotyledon found in this class to represent one of the ancestral pair, the second having been suppressed. Agardh, however, suggested in I 829 that in some Monocotyledonous families the single cotyledon might represent a fusion of the Dicotyledonous pair. This suggestion seems to have been founded partly on a misinterpretation of the seed-structure of Nymphaea and its allies, and it fell into oblivion.

The most important paper published of late years in support of the first of these alternatives is that of Professor Henslow (published in the Linnean Journal for 1892 (38)). He assumes a common origin for both classes, and collects a quantity of evidence to show :- -

I. That Monocotyledons are derived from a stock essentially Dicotyledonous ; that is, possessing two cotyledons, a true cambium, and some of the minor characters of Dicotyledons.

2. That the single cotyledon of Monocotyledons represents one of those possessed by the ancestral stock, the other having been suppressed.

3. That the features characteristic of Monocotyledons were evolved during the adaptation of one or more branches of the ancestral stock to an aquatic habit.

With regard to the first proposition we have seen that existing evidence is altogether in favour of supposing Primitive Angiosperms to have possessed a true cambium and two cotyledons. The evidence advanced in support of the two succeeding propositions may be criticized.

Professor Henslow points out that a very large proportion of Monocotyledonous orders are aquatic-about 33 per cent. as compared with 4 per cent. of Dicotyledonous orders. When a class or an order contains aquatic forms only, it is reasonable to conclude, in the absence of evidence to the contrary, that the common ancestor of that class or order was aquatic also. But the existence of a large minority of aquatic orders within a class may be equally well explained on grounds other than the descent of all members of that class from an aquatic stock. In this case I believe that Monocotyledons may be shown to be on the whole a decadent race of which some branches have been driven to an aquatic habit to escape the severer competition on land. 
Monocotyledons are, on the whole, a far less vigorous class than Dicotyledons; as a rule their representatives are found under rather exceptional conditions. Thus Palms do not extend far beyond the tropics; bulbous and tuberous families (Liliaceae, Iridaceae, \&c.) are characteristic of Alpine situations and dry climates with periodical rains. Almost the only Monocotyledons which compete successfully with Dicotyledons over a wide range are the Grasses.

Professor Henslow has remarked on the large proportion of small orders found among Monocotyledons. Considering this character, together with the peculiarities of distribution just mentioned, they may perhaps be considered as a class which has seen better days:-as survivals from a period in which they were more numerous and more widely spread than in the present geological epoch. I shall endeavour later on to show that such an hypothesis is not unreasonable ; if it be granted, we may look on living Monocotyledons as a race which has been on the whole unsuccessful in the struggle for existence, and in consequence maintains itself chiefly in situations where the local conditions are exceptionally favourable to its peculiar characters.

The number of small aquatic orders found among Monocotyledons is easily explained by this hypothesis, for among animals and plants alike many ancient forms have survived by adapting themselves to life in small ponds or in streams where the competition for existence is less keen than under more genial conditions.

A mass of observations has been collected by Professor Henslow to show that features characteristic of Monocotyledons occur chiefly or exclusively among aquatic Dicotyledons, when found in that class at all. Only a few of these observations can be mentioned here; I have attempted to pick out the most important.

(i) Arrest of one Cotyledon.

The examples given are Trapa natans, Ranunculus Ficaria, and Carum Bulbocastanum. Of these only Trapa natans is aquatic, and it is, so far as I know, the only instance among aquatic Dicotyledons in which one cotyledon is absent or much reduced. As a rule they possess two, often specialized as food-storers. On the other hand, there are at least twelve other species of Dicotyledons distinguished by possessing one cotyledon only (Sargant, 72, p. 76). Not one of them is aquatic, but they are all geophilous, and most of them very highly specialized to that habit.

(ii) Sheathing petioles.

The leaves of Monocotyledons are commonly expanded at the base into a broad sheath, which encloses the bases of the younger leaves more or less completely. The petiole of some Dicotyledons is expanded at the base 
in a similar way, and some of these species are aquatic. But sheathing petioles are also found in terrestrial Dicotyledons : for instance, in many Umbellifers.

In Monocotyledons the connexion is clear between the formation of a sheathing petiole and the suppression of stem internodes. Both characters are correlated with the formation of a large bud on a squat subterranean axis-a character so common in this class. The bud is commonly dormant throughout the winter, and sends up leaves and flowers in the spring. In such an axis the internodes are disk-shaped, and for the adequate insertion of radical leaves a broad base is necessary. In a large underground bud, moreover, the protection of one leaf by the expanded base of that outside it is very convenient.

The aquatic Dicotyledons with sheathing petioles are forms such as Nymphaea, having rhizomes which creep in the mud at the bottom of the pond and send green shoots upwards into the water. The green shoots die down in the winter like the aerial shoots of geophytes. Moreover the terrestrial Dicotyledons with sheathing petioles are mainly geophytes; that is, species with underground stems which throw up aerial shoots each spring to die down in the winter.

In short, the character which all these Dicotyledons with sheathing petioles have in common is not the aquatic but the geophilous habit. Aquatics, such as Nymphaea, which have a permanent axis beneath the mud at the bottom of the ponds where they grow, have some characters in common with geophytes.

(iii) Stem anatomy.

Similar criticism applies to Professor Henslow's remarks on the anatomy of the stem. He explains with great clearness how a number of broad-based leaves inserted on a squat axis introduce more traces into that axis than can be accommodated in a single circle. Hence the formation of several concentric circles of traces. Secondary thickening is not usually required in such a stem. The intrafascicular cambium soon disappears, particularly when starch and other food-stuffs are packed in the conjunctive tissue which separates the bundles. But traces of cambium within each bundle are commonly found in geophilous Dicotyledons.

But though this explanation may-and probably does-account for the scattered arrangement of bundles in the rhizomes of many aquatic Dicotyledons, the character belongs exclusively to the permanent axis rooted in the soil beneath the water. The vascular tissue of the axes which grow upwards into the water is always very much reduced in quantity. The stele of completely submerged stems commonly becomes a slender cylinder in which the leaf-traces lose their identity.

Thus the likeness between the stem anatomy of aquatic Dicotyledons and that characteristic of Monocotyledons in general is confined to the 
underground axes of the former. That likeness is shared by the axes of geophilous Dicotyledons, for example many Umbellifers (Worsdell, 90), Podophyllum (Holm, 45).

When Professor Henslow suggested that all living Angiosperms were derived from a common dicotylar stock, he stood almost alone in that belief. Of late years the tide has begun to turn. More than one botanist has come to the same conclusion on independent grounds. But though their conclusion is the same, these observers are not agreed either with Professor Henslow or with each other on the method by which descendants from the primitive dicotylar stock became Monocotyledonous.

The latest contribution to the subject is that of Mr. A. W. Hill (39). Observations on an apparently monocotylar species of Peperomia, discovered by himself in a high Alpine situation on the Cordilleras, have led him to the conclusion that there are in fact two cotyledons present in the seedling. One is hypogeal and acts as a sucker ; the other has assumed the appearance and functions of the foliage leaf. The species is-as might be expected from its habitat-very markedly geophilous in structure. Its seedlings seem to germinate in the spongy herbage of the locality. They are small, and their vascular tissue is so much reduced as to give them the appearance of aquatic seedlings, such as those of Alisma.

Mr. Hill's interpretation of the structure of these seedlings may be correct, but it is always necessary to be cautious in dealing with the homology of members much reduced from any cause. If, however, the seedlings of one species of a dicotyledonous genus have really become apparently monocotylar by the transformation of the second cotyledon into a foliage leaf, Mr. Hill has discovered a new method by which a dicotylar seedling may become monocotylar. He suggests that Monocotyledons may have been evolved in a similar way.

The vascular structure of seedling Monocotyledons does not support this view. One of the most striking features in it is the distinct vascular symmetry of the cotyledon and the first leaf $\left(72\right.$, pp. $\left.3^{8-40}\right)$. The cotyledon in the great majority of cases has no midrib. It is replaced either by a double bundle or by two single and quite distinct bundles. In the exceptional cases the apparently single midrib often shows its double character during the transition (Zygadamus), or is allied to-and probably derived from-forms with the more usual dual structure (Veratrum). The first leaf, on the other hand, always has a midrib, and commonly one pair at least of lateral bundles. This structure is repeated in all subsequent leaves. Schlickum describes three species of Monocotyledons in which the cotyledon closely resembles the first leaf. All three are aquatic plants: Triglochin Barretieri, T. maritimum, and Alisma Plantago (77, pp. 4-8). The vascular tissue is much reduced in all these plants owing to their aquatic 
habit, and the cotyledon and first leaf alike have a single median bundle. The first leaf has two laterals in addition.

If the second cotyledon of the ancestor had really been transformed into the first foliage leaf, we should expect to find some traces of cotyledonary anatomy within it in forms not obviously reduced. But, on the contrary, the less reduced forms are those in which the anatomical contrast between cotyledon and first leaf is most conspicuous.

A third hypothesis is that both cotyledons of the ancestor united to form the single cotyledon of Monocotyledons. This view arises naturally from the comparative study of Monocotyledonous seedlings, and has already been discussed from the anatomical standpoint. But it is supported also by general considerations. I have already published the scheme founded on this hypothesis $(72,73)$. It suggests that the fusion of cotyledons which gave rise to the early Monocotyledons was an adaptation to a geophilous habit.

Two questions arise immediately out of that suggestion :

I. How could adaptation to a geophilous habit lead to fusion of the cotyledons?

2. Would it account for the peculiar stem-anatomy of Monocotyledons, and for some at least of the minor features which separate that class from Dicotyledons?

Before attempting to answer those questions, the characters of geophilous plants must be more fully considered.

Geophilous plants or geophytes are species which have their permanent axis underground. Their green organs are produced at the beginning of each growing season, and die down at the end of it. But this is a very wide definition. It would include all the forms known to gardeners as herbaceous perennials, besides the more specialized 'alpines' and 'bulbs'.

The more specialized geophytes are natives to climates in which a short season of growth is followed by a long period in which the conditions are unfavourable to vegetation. Such are alpine and arctic situations, where the summer may not last three months, and the ground is buried in snow for at least nine; or dry climates with periodic rains, as on the South African veldt, and in localities of the Mediterranean region. Geophytes form a large proportion of the flora in such climates. They are characterized by massive underground organs, which in the dead season represent the whole plant. At that epoch it consists of a squat axis, often much enlarged to serve as a storehouse for food, and of one or more buds, which will produce the aerial organs in the next season. Roots may or may not be present. Some geophytes (e. g. Massonia pustulata) have permanent roots which last over the dead season. Others (as many Orchids) have tuberous roots for aerial food-storage in place of tuberous stems. But the rule is that roots, like shoots, last over one growing season only, and die down at the end of it. 
The linear leaves of Monocotyledons are particularly well adapted to sudden elongation in order to pierce the soil in the spring, when the ground is moist with the melting snow, or the first rains. The rapid production of flowers and leaves is a point of great importance to a geophyte. Every hour of the short season is precious-to the leaves for assimilation, to the flowers for ripening seed.

Another feature characteristic of a geophyte is the long interval which commonly elapses between the sowing of its seeds and their germination. This is a peculiarity only too familiar to gardeners who raise bulbous and alpine plants from seed. It is correlated with the very immature condition of the embryo in the ripe seed. Among many examples, I may quote the particulars as to the germination of Ramunculus Ficaria given by M. Sterckx (83). The embryo in the ripe seed of this plant is a small, spherical, undifferentiated mass of meristem attached to a short suspensor. Seeds sown immediately on ripening-that is, in May, 1896 - did not germinate until the early spring of 1898 (pp. $42-3$ ). ${ }^{1}$ At the time of germination, cotyledon, plumule, and primary root were all indicated in the embryo, which had increased enormously in size.

This deliberate maturation of the embryo is correlated with the geophilous habit. For the plant has a struggle to get the seed ripened at all within its short growing season. To place the germ of the future plant in safety is the one essential : to provide it with food, and to protect it from the bad weather. This accomplished, the whole of the next growing season may well be devoted to the maturation of the embryo, while its germination is postponed to the third season. Hence the seeds of wellmarked geophytes are commonly albuminous, and their embryos not only small but quite undifferentiated.

When germination at last takes place, the geophilous seedling makes but little show above ground. Sometimes, indeed, it remains below the surface during the first season after germination (Arum maculatum, Vevatrum nigrum). But this is exceptional: as a rule at least one green part appears in the first year. It may be the cotyledon, as in Fritillaria, or the first leaf, as in Crocus. The fact that all Dicotyledons with one seed-leaf are geophilous has been mentioned already. So are those in which the cotyledons are partially united, as in Podophyllum, with the solitary exception of Rhizophora (72, pp. 73 and $77-8)$. It would seem, then, that the geophilous seedling observes a strict economy in its aerial organs during the first season of growth.

The explanation of this economy - already given elsewhere (72, pp. 80-I, and 73, p. 353)-may be shortly repeated here. The seedling has to face the return of bad weather at the end of a short growing period. If it is not

1 Two seeds among a large number are stated by M. Sterckx (83) to have germinated in 1897. Dr. Schmid in South Germany (78), and Mr. McDonald in Lancashire (59), found that seeds sown early out of doors commonly germinate in the following year. No dorbt this discrepancy depends on a difference of climate. 
well sheltered from adverse conditions by the end of its first season, it will not survive to the next. Geophilous seedlings take shelter in the earth. Hence their underground organs are of the first importance. A bud must be formed, protected both by its coverings and by the soil in which it is sunk. It must be provided with food on which to start growth when the genial weather returns. The provision of such a bud in the limited period allowed to the seedling taxes its resources. Only a very small aerial shoot can be afforded in addition, even though in the end the green parts more than pay their way.

The first question proposed on page I79 has been already answered. The geophilous habit is correlated with partial fusion of the two cotyledons in some Dicotyledons, and with a single cotyledon in others. Supposing one branch of descendants from the Primitive Angiosperms to become geophilous, the green parts of their seedlings would inevitably be reduced in the early seasons of growth. In the first season this reduction might well take the form of partial fusion of both cotyledons, leading to complete fusion.

The second question can perhaps be answered most graphically by describing a concrete instance. The seedling of Podophyllum peltatum has been fully described by $\mathrm{Mr}$. Holm (45). Its cotyledons are united into a long tube: the blades alone are distinct. We have already seen that its vascular symmetry recalls that of a Monocotyledon (p. I73, and Figs. I92I). The anatomy of the erect stem in the mature plant is markedly Monocotyledonous (Holm, 45, and Solereder, 81, p. 52). The radical leaves are net-veined, but their petioles are expanded at the base into a sheath from which many traces enter the subterranean stem-bud. Mr. Holm has shown how the scattered disposition of bundles in the stem follows from this arrangement. The traces in the erect stem have lost their cambium-they are closed like those of a Monocotyledon-but cambium is found in the bundles of the rhizome. These are arranged in a single circle, but without intrafascicular cambium.

Podophyllum peltatum grows in swampy woods in the Southern States of North America. Its squat underground axis, packed with starch, though not expanded into a tuber, is a geophilous character, probably developed under climatic conditions of greater severity than those of its present habitat. There are bulbous plants in English woods - the bluebell, Scilla festalis, Salisb., for example-which are above the ground in spring and early summer only. At this season such plants are sheltered by the leafless trees without losing much light. But though their geophilous habit enables these species to take advantage of the woodland stations which they now occupy, it was probably acquired elsewhere: inherited perhaps from ancestors living under more stringent conditions. In the case of Podophyllum this is the more likely as the only other species of the genus, P. Emodi, is Himalayan. 
In addition to the Monocotyledonous characters already mentioned, Podophyllum peltatum has a 6-partite perianth.

The partial fusion of the cotyledons and the anatomy of the erect stem in $P$. peltatum can be fairly interpreted as adaptations to a geophilous habit. A Ranal stock with similar characters, if exposed to more stringent conditions of the same kind, might easily go on to complete fusion of the cotyledons. It might not develop the lateral underground shoots which enable $P$. peltatum to spread in its swampy habitat, but the squat underground axis would probably be enlarged into a tuber with a fresh crop of root, each season. The aerial shoots would certainly be reduced in size. Such a form would not be far removed from a true Monocotyledon.

Several objections to the geophilous origin of Monocotyledons which have been urged, or have occurred to me independently, may be considered here.

It has been suggested that so large a class as Monocotyledons, and one so varied in habit, is not likely to spring from a race of plants so highly specialized to peculiar conditions. A plant may, however, be distinctly geophilous without being so completely adapted to its immediate surroundings that its descendants can never change their habit. The geophilous primary axis of Podophyllum peltatum has not prevented it from acquiring the rhizome suited to a swampy station. Indeed, a geophyte which has not developed a pronounced tuber or bulb can readily adapt itself to an aquatic life. Its underground stem roots first in the muddy banks, and thence advances into the bed of a pond or stream. In the course of generations its aerial shoots become more and more adapted to submersion. Many comparatively ancient Monocotyledons, such as Alisma, have perhaps escaped extinction by taking possession of such situations.

Climbers, again, often possess massive underground stems from which aerial shoots are sent up every year (Bryonia, Tamus).

The geophilous structure of the stem is certainly unfavourable to the evolution of trees. This is perhaps the line in which Monocotyledons are least successful. No Monocotyledonous tree can compete with Dicotyledons outside the tropics. Within them, Palms have contrived to overcome the disadvantages of an essentially geophilous structure. The early growth of Palms, the slow formation of their axis in their early years by the addition of one disk after another to a squat subterranean stem, the close connexion of the early leaves with their special roots, all point clearly to a geophilous period in the history of the race (cf. Sargant, 73, p. 344).

The conditions of life which encourage geophilous characters are very local at the present time. Alpine summits are necessarily isolated : dry climates with periodic rains occur in limited regions scattered all over the globe. It is certainly difficult to conceive how a race formed in any one 
of these localities should reach the others and spread all over the globe as Monocotyledons have done. But conditions may have been more favourable in an earlier geological epoch. During the glacial periods the winter in Europe and Northern Asia was much longer and colder than at present: the summer shorter and warmer. The Alpine flora of this continent is supposed to represent the survivors of a flora which spread all over it during these epochs. On such a stage as this the great drama of the evolution of Monocotyledons might well be played with success.

The geophilous habit does not, so far as I can see, explain the ternate floral symmetry of Monocotyledons. Whorls of three and six parts are not uncommon in the flowers of the Ranales. It is possible that they are inherited from an ancestor which this alliance has in common with Monocotyledons. I agree with Messrs. Arber and Parkin in believing that the stamens and carpels of the Primitive Angiosperm were indefinite in number and spiral in arrangement. The perianth may, however, have been in whorls of three or six.

The hypotheses which have been considered with regard to the number of cotyledons in the Primitive Angiosperm and their morphological nature have led to two phylogenetic schemes only which attempt to explain the evolution of Monocotyledons and Dicotyledons from a common ancestor. The first is that of Professor Henslow which derives Monocotyledons from a dicotylar race by suppression of one cotyledon and adaptation to an aquatic habit. The second is the fusion hypothesis. The two cotyledons of Primitive Angiosperms have united to form the single member in Monocotyledons. This union, as well as the peculiarities of stem anatomy, and many of the minor characters in Monocotyledons, are due to adaptation to a geophilous habit.

Both schemes, it will be observed, give the Primitive Angiosperm two cotyledons and the stem anatomy of a Dicotyledon. Most of the minor characters which distinguish Monocotyledons are also treated in both schemes as departures from the primitive type. It is probable, therefore, that the Primitive Angiosperm resembled Dicotyledons much more nearly than Monocotyledons in their general features, as well as in stem anatomy and the possession of two cotyledons.

Quarry Hill, Reigate.

Jan. 20, 1908.

\section{REFERENCES TO LITERATURE.}

1. Anderssohn, S. : Ueber die Entwickelung der primären Gefässbündelstränge der Monokotylen. Bihang till K. Svensk. Vet. Akad. Handl., xiii, I 888.

2. Anonymous : Discussion on the Vascular Structure of Seedlings. New Phytologist, v, p. i8z, I906. 
3. Arber, E. A. N., and Parkin, J.: The Origin of Angiosperms. (Paper read at the Linnean Soc. on March 2 I, 1907.) Proc. Linn. Soc., cxix, I906-7, p. I3.

4. xxxviii, 1907, p. 29.

5. Baillon, H. : Histoire des plantes : Monographie des Liliacées. Paris, I894.

6. Baker, J. G.: A Revision of the Genera and Species of Herbaceous Capsular Gamophyllous Liliaceae. Journ. Linn. Soc. Bot., xi, I870, p. 349.

7. - A Revision of the Genera and Species of Scilleae and Chlorogaleae. Journ. Linn. Soc. Bot., xiii, 1872 , p. 209.

8. Balfour, J. B. : Presidential Address to Section K of the British Association, I90 I.

9. Benson, M.: The Origin of Flowering Plants. New Phytologist, iii, I904, p. 49.

10. Benson, M., Sanday, E., and Berridge, E. : Embryology of the Amentiferae, II. Carpinus Betulus. Trans. Linn. Soc., vii, I906, p. 37 .

11. Berridge, E. M.: The Origin of Triple Fusion. New Phytologist, vi, I907, p. 279.

12. Berridge, E. M., and Sanday, E.: Oögenesis and Embryogeny in Ephedra distachya. New Phytologist, vi, 1907 , pp. I 27 and 167.

13. Bower, F. O.: On the Germination and Histology of the Seedlings of Welvuitschia mirabilis. Quart. Journ. Micr. Sci., xxi, I88I, p. I5.

14. : The Germination and Embryogeny of Gnetum Gnemon. Quart. Journ. Micr. Sci., xxii, r 882 , p. 278 .

15. Campbell, D. H.: A peculiar Embryo-sac in Peperomia pellucida. Ann. of Bot., xiii, i899, p. 626.

16. Celakovsky, L. J. : Die Gliederung der Kaulome. Bot. Zeit., lix, Pt. I, I90I, p. 79.

17. Cormack, B. G.: On a Cambial Development in Eqquisetum. Ann. of Bot., vii, 1893, p. 63.

18. Coulter, J. M. : Phylogeny of Angiosperms. Decennial Publications of the University of Chicago, I903.

19. Coulter, J. M., and Chamberlain, C. J. : Morphology of Angiosperms, New York, I903.

20. Dangeard, P.: Recherches sur le mode d'union de la tige et de la racine. Le Botaniste, i, 1889 .

21. Darwin, F. : Elements of Botany, p. 22, Fig. 5. Cambridge, I905.

22. Eichler : Pflanzenfamilien, II : I. Gymnospermen. Leipzig, I889.

23. ERnst, A. : Chromosomenreduction, Entwickelung des Embryosackes, und Befruchtung bei Paris quadrifolia und Trillium grandiflorum. Flora, xci, I902, P. I.

24. : Der Befruchtungsvorgang bei den Blithenpflanzen. Mittheil. d. naturw. Ges. in Winterthur, Heft v, I904, p. 200.

25. Fleischer, E.: Beiträge zur Embryologie der Monokotylen und Dikotylen. Flora, i874.

26. Frye, F. C. : The Embryo-sac of Casuarina stricta. Bot. Gaz., xxxvi, I903, p. IOI.

27. GÉrard, R.: Recherches sur le passage de la racine à la tige. Ann. des Sci. Nat., sér. 6, Botanique, ii, 1881 , p. 7 .

28. GibBs, L. S.: Notes on the Development and Structure of the Seed in the Alsinoideae. Ann. of Bot., xxi, 1907 , p. 25.

29. Guérin, P. : Sur le sac embryonnaire des Gentianes. Journ. de Bot, xvii, I903, p. IоI.

30. - Les connaissances actuelles sur la fécondation chez les Phanérogames. Paris, 1904.

31. Guignard, L.: Recherches d'embryogénie comparée. I. Légumineuses. Ann. des Sci. Nat., sér. 6 , Botanique, xii, I88 I, p. 5 .

32. - Sur les anthérozöides et la double copulation sexuelle chez les végétaux angiospermes. Compt. Rend., cxxviii, 1899, p. 864, and Revue de Botanique, xi, I899, p. I 29.

33. - L L'appareil sexuel et la double fécondation dans les Tulipes. Ann. des Sci. Nat., sér. 8 , Botanique, xi, 1900, p. 365 .

34. Hallier, H. : Provisional Scheme of the Natural . . System of Flowering Plants. New Phytologist, iv, I $_{90} 5$, p. I 5 I.

35. Hanstein, J.: Die Entwickelung des Keimes der Monokotylen und Dikotylen. Hanstein's Botanische Abhandlungen, Bonn, i, 1870 .

36. Hegelmaier, F.: Zur Entwickelungsgeschichte monocotyledoner Keime, nebst Bemerkungen iiber die Bildung der Samendeckel. Bot. Zeit., xxxii, I874.

37. - Vergleichende Untersuchungen über Entwickelung dikotyledoner Keime。 Stuttgart, 1878 . 
38. Henslow, G.: A Theoretical Origin of Endogens from Exogens by Self-adaptation to an Aquatic Habit. Linn. Soc. Journ., xxix, $189^{2}, \mathrm{p} .4^{8} 5$.

39. Hill, A. W.: Morphology and Seedling Structure of the Geophilous species of Peperomia, together with some views on the Origin of Monocotyledons. Ann. of Bot., xx, 1906, p. 395.

40. Hill, T. G. : On the Seedling Structure of certain Piperales. Ann. of Bot., xx, I906, p. I6I.

41. : On the Seedling Structure of certain Centrospermae. Ann. of Bot., xx, I906, p. 473 .

42. Hill, F. G., and De Fraine, E.: On the Seedling Structure of Gymnosperms. Ann. of Bot., $\mathrm{xx}, \mathrm{I} 906, \mathrm{p} .47 \mathrm{I}$.

43. Hofmeister, W.: Vergleichende Untersuchungen der Keimung, Entfaltung, und Fruchtbildung höherer Kryptogamen. Leipzig, I 85 I.

44. - : On the Germination, Development, and Fructification of the Higher Cryptogamia, and on the Fructification of the Coniferae. Trans. by F. Currey, Ray Soc., London, 1862 .

45. Holm, Theo.: Podophyllum peltatum. Bot. Gaz., xxvii, I899, p. 4 I9.

46. Jefrerey, E. C.: Comparative Anatomy of Angiosperms. Coulter and Chamberlain's Morphology of Angiosperms, ch. xvii, New York, I903, p. 3II.

47. Johnson, D. S.: On the Endosperm and Embryo of Peperomia pellucida. Bot. Gaz., xxx, I900, p. I.

48. - : On the Development of certain Piperaceae. Bot. Gaz., xxxiv, I902, p. 32 r.

49. — A new Type of Embryo-sac in Peperomia. Johns Hopkins Univ. Circ., no. 3,1907 , p. 19.

50. Karsten, G.: Zur Entwickelungsgeschichte der Gattung Gnetum. Cohn's Beiträge, vi, 1893, p. 337 .

50 a. Flora, xc, I902, p. 316 .

51. $\mathrm{Koch}$, L.: Untersuchungen über die Entwickelung der Cuscuteen. Hanstein's Botanische Abhandlungen, Bd. ii, Heft 3. Bonn, 1874 .

52. Le Maout and Decaisne: Descriptive and Analytical Botany. English ed. trans. by Mrs. Hooker, London, 1876.

53. Le Monnier, G.: Sur la valeur morphologique de l'albumen chez les Angiospermes. Journ. de Bot., i, I887, p. I 4 o.

54. Lloyd, F. E. : The Comparative Morphology of the Rubiaceae. Mem. Torr. Bot. Club, viii, 1899-1902.

55. Lotsy, J. P.: A Contribution to the Life-History of the Genus Gnetum. Ann. Bot. Buit., xvi, 1899, p. 46.

56. Lyon, H. L. : Embryogeny of Nelumbo. Minnesota Bot. Studies, ii, I901, p. 643 .

57. - : The Phylogeny of the Cotyledon. Postelsia, I90r, p. 57.

58. - The Embryo of the Angiosperms. American Naturalist, xxxix, I 905, p. I3.

59. McDonald, J. E.: The Lesser Celandine. The Naturalist's Journal, xi, Nov. 1902, p. 187.

60. Matte, H.: Recherches sur l'appareil libéro-ligneux des Cycadées. Caen, I904.

61. Nawaschin, S.: Nene Beobachtungen ïber Befruchtung bei Fritillaria tenella und Lilium Martagon. Paper read before the Russian Congress of Naturalists in Kiew, Aug. 24, 1898. Ref. in Bot. Centralb., lxxvii, Jan. 4, 1899, p. 62.

62. Oliver, F. W.: Pteridosperms and Angiosperms. New Phytologist, v, 1906, p. 232.

63. PACE, L. : Fertilization in Cypripedium. Bot. Gaz., xliv, 1907, p. 353.

64. Pearson, H. H. W.: Some Observations on Welwitschia mirabilis. Phil. Trans., B., cxcviii, London, 1906, p. $26_{5}$.

65. Quéva, C.: Contributions à l'anatomie des Monocotylédonées: I. Les Uvulariées tubéreuses. Travaux et Mémoires de l'Université de Lille, I899.

66. Ramaley, F.: The Cotyledons and Leaves of certain Papilionaceae. Univ. of Colorado Studies, vol, i, 1903, p. 239.

67. : A Study of certain Foliaceous Cotyledons. Univ. of Colorado Studies, vol. ii, 1905 , p. 255 .

68. Rober'rson, C.: The Structure of the Flowers and the Mode of Pollination of the Primitive Angiosperms. Bot. Gaz., xxxvii, 1904, p. 294.

69. Sachs, J. : History of Botany, I 530-I 860 . Eng. Ed., Oxford, I 890. 
70. Sargant, E.: A New Type of Transition from Stem to Root in the Vascular System of Seedlings. Ann. of Bot., xiv, I900, p. 633 .

71. - The Origin of the Seed Leaf in Monocotyledons. New Phytologist, i, 1902, p. 107.

72. $:$ A Theory of the Origin of Monocotyledons, founded on the Structure of their Seedlings. Ann. of Bot., xvii, I903, p. I.

73. ㄴ : Evolution of Monocotyledons. Bot. Gaz., xxxvii, I904, p. 325 .

74. Sargant, E., and Robertson, A.: The Anatomy of the Scutellum in Zea Mais. Ann. of Bot., xix, 1905 , p. II 5 .

75. Schaff ner, J. H.: The Life-history of Sagittaria variabilis. Bot. Gaz., xxiii, 1897, p. 252.

76. Schaffner, Mabel: The Embryology of the Shepherd's Purse. Ohio Naturalist, vii, I906, p. I.

77. Schlickum, A.: Morphologischer und anatomischer Vergleich der Kotyledonen und ersten Laubblätter der Keimpflanzen der Monokotylen. Bibliotheca botanica, xxxv, I 896 .

78. Schмid, B. : Beiträge zur Embryo-Entwickelung einiger Dicotylen. Bot.Zeit., lx, 1902, p. 207.

79. Schnegg, H. : Beiträge zur Kenntniss der Gattung Gunnera. Flora, xc, 1902, p. 16I.

80. Scott, D. H.: The Flowering Plants of the Mesozoic Age, in the Light of Recent Discoveries. Journ. Roy. Micr. Soc., 1907, pp. I 29-14I.

80 a. Seward, A. C. : Presidential Address to Section K., British Association, 1903.

81. Solereder, H. : Systematische Anatomie der Dicotyledonen. Stuttgart, I 899.

82. Solms-Laubach, H. Graf ZU : Ueber monocotyle Embryonen mit scheitelbürtigem Vegetationspunkt. Bot. Zeit., xxxvi, 1878 , p. 65 .

83. Sterckx, R.: Recherches anatomiques sur l'embryon et les plantules dans la famille des Rénonculacées. Mém. Soc. Roy. Sci. de Liège, iii, vol. ii, I899.

84. Strasburger, E. : Ueber Befruchtung unả Zelltheilung. Leipzig, I 878 .

85.

86. - Die Samenanlage von Drimys Winteri und die Endospermbildung bei Angiospermen. Flora, Erg.-bd. 1905, p. 215.

87. Tansley, A. G., and Thomas, E. N.: The Phylogenetic Value of the Vascular Structure of Spermophytic Hypocotyls. Report of Brit. Ass., Section K., I906, p. 76r.

88. Thоmas, E. N.: A Theory of the Double Leaf-trace founded on Seedling Structure. New Phytologist, vi, 1907, p. 77.

89. Wieland, G. R. : American Fossil Cycads. Carnegie Institute, Washington, 1906.

90. Worsdell, W. C.: The Nature of the Vascular System of the Stem in certain Dicotyledonous Orders. Ann. of Bot., xvi, p. 599.

91. Zeiller, R. : Les progrès de la paléobotanique de l'ère des Gymnospermes. Progressus Rei Botanicae, ii, 1907, p. I 7 I. 


\section{$2 \mathrm{BHL}$ Biodiversity Heritage Library}

Sargant, Ethel. 1908. "The reconstruction of a race of primitive angiosperms." Annals of botany 22, 121-186.

https://doi.org/10.1093/oxfordjournals.aob.a089165.

View This Item Online: https://www.biodiversitylibrary.org/item/232525

DOI: https://doi.org/10.1093/oxfordjournals.aob.a089165

Permalink: https://www.biodiversitylibrary.org/partpdf/318901

\section{Holding Institution}

Smithsonian Libraries

\section{Sponsored by}

Biodiversity Heritage Library

\section{Copyright \& Reuse}

Copyright Status: Not in copyright. The BHL knows of no copyright restrictions on this item.

This document was created from content at the Biodiversity Heritage Library, the world's largest open access digital library for biodiversity literature and archives. Visit BHL at https://www.biodiversitylibrary.org. 